\title{
Dural arteriovenous fistulas of the hypoglossal canal: systematic review on imaging anatomy, clinical findings, and endovascular management
}

\author{
Björn Spittau, MD, ${ }^{1}$ Diego San Millán, MD, ${ }^{2}$ Saad El-Sherifi, MD, ${ }^{3}$ Claudia Hader, MD, ${ }^{3,4}$ \\ Tejinder Pal Singh, MD, ${ }^{5}$ Edith Motschall, ${ }^{6}$ Werner Vach, PhD, ${ }^{6}$ Horst Urbach, MD, ${ }^{3}$ \\ and Stephan Meckel, MD ${ }^{3}$
}

\begin{abstract}
${ }^{1}$ Institute for Anatomy and Cell Biology, Department of Molecular Embryology, Albert-Ludwigs-University Freiburg; ${ }^{3}$ Department of Neuroradiology, University Hospital Freiburg; ${ }^{6}$ Center for Medical Biometry and Medical Informatics, Medical Center-University of Freiburg, Germany; ${ }^{2 N e u r o r a d i o l o g y}$ Unit, Department of Diagnostic and Interventional Radiology, Centre Hospitalier du Centre du Valais, Hôpital de Sion; ${ }^{4}$ Neuroradiology Unit, Institute of Radiology, Kantonsspital St. Gallen, Switzerland; and ${ }^{5}$ Neurological Intervention and Imaging Service of Western Australia, Sir Charles Gairdner \& Royal Perth Hospitals, Nedlands, Western Australia, Australia
\end{abstract}

Dural arteriovenous fistulas (DAVFs) of the hypoglossal canal (HCDAVFs) are rare and display a complex angiographic anatomy. Hitherto, they have been referred to as various entities (for example, "marginal sinus DAVFs") solely described in case reports or small series. In this in-depth review of HCDAVF, the authors describe clinical and imaging findings, as well as treatment strategies and subsequent outcomes, based on a systematic literature review supplemented by their own cases (120 cases total). Further, the involved craniocervical venous anatomy with variable venous anastomoses is summarized. Hypoglossal canal DAVFs consist of a fistulous pouch involving the anterior condylar confluence and/ or anterior condylar vein with a variable intraosseous component. Three major types of venous drainage are associated with distinct clinical patterns: Type 1, with anterograde drainage (62.5\%), mostly presents with pulsatile tinnitus; Type 2, with retrograde drainage to the cavernous sinus and/or orbital veins (23.3\%), is associated with ocular symptoms and may mimic cavernous sinus DAVF; and Type 3, with cortical and/or perimedullary drainage (14.2\%), presents with either hemorrhage or cervical myelopathy. For Types 1 and 2 HCDAVF, transvenous embolization demonstrates high safety and efficacy (2.9\% morbidity, $92.7 \%$ total occlusion). Understanding the complex venous anatomy is crucial for planning alternative approaches if standard transjugular access is impossible. Transarterial embolization or surgical disconnection (morbidity 13.3\%-16.7\%) should be reserved for Type 3 HCDAVFs or lesions with poor venous access. A conservative strategy could be appropriate in Type 1 HCDAVF for which spontaneous regression (5.8\%) may be observed.

http://thejns.org/doi/abs/10.3171/2014.10.JNS14377

KEY WORDS dural arteriovenous fistula; hypoglossal canal; anterior condylar confluence; anterior condylar vein; skull base vein; endovascular therapy; transvenous embolization; vascular disorders

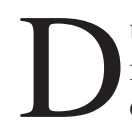
URAL arteriovenous fistulas (DAVFs) are abnormal communications between dural arteries and dural venous sinuses, meningeal veins, or cortical veins. ${ }^{20}$ They account for $10 \%-15 \%$ of intracranial arteriovenous malformations and are classified according to the location of the involved sinus, that is, transverse, sig- moid, or cavernous sinus DAVFs. ${ }^{20}$ These fistulas can also occur at the skull base, in which case a dural venous sinus may not be directly involved. Grading DAVFs is based on the direction of venous flow within the dural venous sinus (anterograde vs retrograde) and the presence of cortical venous reflux..$^{7,14}$

\footnotetext{
ABBREVIATIONS ACC = anterior condylar confluence; $\mathrm{ACV}=$ anterior condylar vein; AIVVP = anterior internal vertebral venous plexus; $C T A=\mathrm{CT}$ angiography; $\mathrm{DAVF}$ = dural arteriovenous fistula; DSA = digital subtraction angiography; EVT = endovascular treatment; HCDAVF = hypoglossal canal DAVF; ICAVP = internal carotid artery venous plexus (of Rektorzik); IJV = internal jugular vein; IPS = inferior petrosal sinus; LCV = lateral condylar vein; MEV = mastoid emissary vein; MRA = magnetic resonance angiography; NBCA = N-butyl cyanoacrylate; PCV = posterior condylar vein; $P T=$ pulse-synchronous tinnitus; $P V A=$ polyvinyl alcohol; SOV = superior ophthalmic vein; TAE = transarterial embolization; TOF = time-of-flight; TVE = transvenous embolization; VA = vertebral artery; VAVP = vertebral artery venous plexus; $\mathrm{VVP}=$ vertebral venous plexus.
}

SUBMITTED February 18, 2014. ACCEPTED October 7, 2014.

INCLUDE WHEN CITING Published online November 21, 2014; DOI: 10.3171/2014.10.JNS14377.

DISCLOSURE The authors report no conflict of interest concerning the materials or methods used in this study or the findings specified in this paper. 
Dural arteriovenous malformations in the region of the hypoglossal canal (HCDAVFs) represent a rare subtype of DAVFs involving the anterior condylar confluence (ACC) and/or the anterior condylar vein (ACV). Their incidence in the literature could be underestimated, as they are often misclassified into other subtypes of DAVFs or referred to as DAVFs of the inferior petrosal sinus (IPS), jugular bulb, marginal sinus, skull base, or foramen magnum, which may further hinder their detection. ${ }^{13,17,31,47,52,55,71} \mathrm{In}$ recent small single-center series, HCDAVFs represented $3.6 \%-4.2 \%$ of all intracranial DAVFs, ${ }^{13,45}$ otherwise, they have mainly been reported as case reports or smaller case series. The location around the ACC or ACV predisposes HCDAVFs to complex venous connections with the orbit, the posterior fossa dural venous sinuses, and the external and internal vertebral venous system. This rich potential for venous connections translates into a polymorphic clinical presentation that may mimic fistulas in other locations such as cavernous sinus DAVFs. ${ }^{12,17,64}$ Moreover, the complex drainage patterns and connections may prove challenging for treatment strategies, in particular for transvenous embolization (TVE).

The advent of high-resolution 3D angiographic imaging techniques allows for the precise anatomical depiction of the fistulous point around the hypoglossal canal, providing invaluable information regarding drainage routes and therapeutic planning.

The goal of the present study was to perform a systematic literature review of all previously published cases of HCDAVF supplemented by HCDAVF cases from our own institutions. To facilitate understanding of HCDAVFs, a summary of the complex venous anatomy at the skull base is provided. Hypoglossal canal DAVFs are analyzed with regard to clinical presentation, imaging findings, variable venous drainage patterns, treatment strategies, outcome, and complications. Finally, we advance recommendations on how to diagnose and manage these rare types of intracranial DAVFs.

\section{Anatomy of the ACC and ACV}

The ACC is a constantly observed small venous structure (5 $\mathrm{mm}$ in maximal diameter) of the skull base that was largely ignored even after Trolard described it in $1868,{ }^{72}$ until its recent rediscovery. ${ }^{64}$ The ACC is located at the extracranial aperture of the hypoglossal canal at the skull base and, because of its connection to a rich venous network, represents a major venous crossroad. ${ }^{64}$ The ACC, along with the other emissary veins of the skull base such as the posterior condylar vein (PCV) and the mastoid emissary vein (MEV), plays an important role in directing encephalic venous blood to the internal and external vertebral venous plexus (VVP). Indeed, while the internal jugular vein (IJV) represents the major cerebral venous outflow pathway in the supine position, the bulk of venous drainage through the posterior fossa dural venous sinuses is redirected to the vertebral venous system in an upright position. ${ }^{16,64,76}$

The ACC has direct connections with the IJV, IPS, $\mathrm{ACV}$, internal carotid artery of the venous plexus (ICAVP; by way of the inferior petrooccipital vein), and lateral condylar vein (LCV), ${ }^{64,72}$ all of which are venous channels devoid of valves, allowing for multidirectional venous flow (Fig. 1). Of clinical importance is the indirect connection of the ACC to the cavernous sinus by way of the IPS and ICAVP (see Results, Venous Drainage Pathways) ${ }^{64}$ Connections to the vertebral venous system occur mainly through the ACV and LCV. The ACV is the cranial extension of the anterior internal VVP (AIVVP) and runs in the hypoglossal canal, along the hypoglossal branch of the neuromeningeal division of the ascending pharyngeal artery, and forms a plexus around the hypoglossal nerve. Furthermore, the ACV may connect intracranially and extradurally with the basilar plexus. The latter structure allows for indirect connections with the posterior compartment of the cavernous sinus and with the anterior pial brainstem veins via the emissary bridging veins. ${ }^{42,61,69}$ The LCV generally arises from a bridging vein between the ACC and the IJV and connects to the anterior portion of the vertebral artery venous plexus (VAVP) at the level of C-2. It runs laterally to the occipital condyle and may be contained in an osseous canal. ${ }^{72}$ It is thus related to the external vertebral venous system, which may become a major drainage pathway in cases of HCDAVF.

Indirect connections of the ACC and ACV with the IJV and dural venous sinuses of the posterior fossa occur in the following manner: First, the ACC is connected to the superior portion of the IJV or the IJV bulb by one or more bridging veins, allowing for retrograde venous flow into the sigmoid and transverse sinuses in cases of HCDAVF. Second, the ACV is connected to the marginal sinus, with the latter located in the dural layers at the margin of the foramen magnum. ${ }^{74}$ In the literature, there is some confusion over the anatomy of the marginal sinus, some authors considering it equivalent to the terminal (distal) portion of a persistent occipital sinus connecting the torcular herophili with the IJV bulb or sigmoid sinus and/or IJV bulb junction. ${ }^{19}$ San Millán Ruíz et al. ${ }^{64}$ found, based on a corrosion cast study of the cranial venous system, that the marginal sinus is invariably connected to the ACV anteriorly. Posteriorly, the marginal sinus may connect with the veins of the suboccipital region or at times represent the major drainage pathway of a persistent occipital sinus (unpublished data, 2014).

\section{Methods}

\section{Systematic Literature Review}

We aimed to identify in the medical literature all cases of HCDAVF that were described with detailed clinical and angiographic information. The PRISMA (Preferred Reporting Items for Systematic Reviews and Meta-Analyses $)^{53}$ guidelines were followed as far as applicable. The senior author (9 years of neuroangiographic experience) and a biomedical librarian (30 years of experience) reviewed the literature as follows: First, three medical databases (PubMed, Embase, and Web of Science) were systematically reviewed for HCDAVFs, including the various other subtypes of DAVFs that HCDAVFs have been referred to in the past, by applying a dedicated search strategy (Appendix Tables 1-3) updated to September 2013. Retrieved 

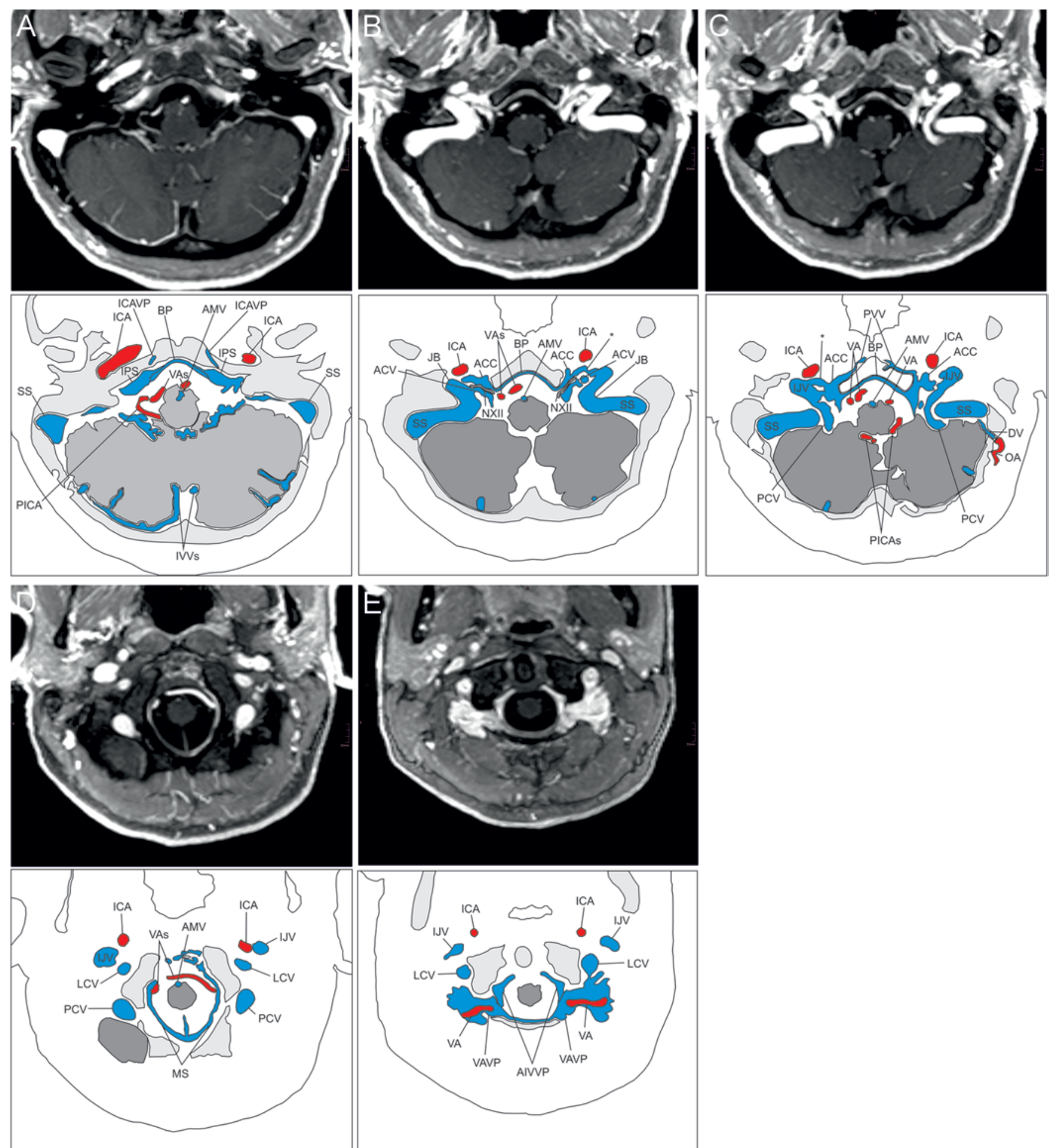

FIG. 1. Depiction of normal venous anatomy at the posterior skull base and craniocervical junction on 5 consecutive axial contrastenhanced MR images (2-mm maximum intensity projection [MIP] reconstructed slices from T1-weighted MPRAGE 3D with fat saturation) from the level of the inferior cerebellar peduncles to the $\mathrm{C} 1-2$ level (A-E). Corresponding schematic diagrams show dedicated arterial (red) and venous (blue) structures at the respective levels. Asterisk indicates venous connections between ACC and IJV and/or JB. AMV = anterior medullary vein; BP = basilar plexus (so-called clival venous plexus); $D V=$ diploic vein; ICA = internal carotid artery; IVV = inferior vermian vein; JB = jugular bulb; MS = marginal sinus; NXII = cranial nerve XII; OA = occipital artery; PICA = posterior inferior cerebellar artery; PVV = prevertebral veins; $S S=$ sigmoid sinus; VAs = vertebral arteries.Copyright Björn Spittau. Published with permission. 
abstracts were prescreened according to clinical descriptions, angiographic findings, and treatment details. Only articles published in the English language were considered. Suitable articles were carefully scrutinized in full text to determine whether they fulfilled the following criteria: comprehensive angiographic and/or cross-sectional imaging findings of DAVF (including arterial feeders, venous drainage, location of fistulous point), clinical presentation and follow-up, and description of treatment (conservative, endovascular, or surgical, including all available details and outcome). Of these articles, those describing suitable subtypes of DAVFs (for example, marginal sinus DAVF) were checked to determine whether the angiographic and anatomical descriptions matched the characteristics and location of an HCDAVF. In many of these reports, the angiographic descriptions and images showed striking similarities to an HCDAVF with respect to fistula points (for example, inferior end of the IPS, medial to jugular bulb for so-called IPS DAVFs), arterial feeders, and venous drainage patterns (antegrade to the IJV and/or VVP, retrograde into the cavernous sinus and the superior ophthalmic vein (SOV), or direct perimedullary drainage via emissary bridging veins). . $^{1,3,5,6,10,31,34,38,41,42,50,58,62,71,81} \mathrm{Sec}$ ond, the latter articles were screened for related articles and references, which were then assessed according to the same aforementioned criteria.

\section{Angiographic Classification of HCDAVF}

McDougall et al. classified venous drainage in HCDAVFs into 3 categories: Grade 1, unrestricted drainage to the region of the ipsilateral jugular bulb; Grade 2, absent or restricted drainage to the ipsilateral jugular bulb; and Grade 3, retrograde cortical venous drainage..$^{47}$ Based on the assessment of HCDAVFs in the present review, we propose a modified classification of the predominant venous drainage pattern into 3 categories relative to the distinct clinical presentation patterns: Type 1, dominant anterograde venous drainage to the IJV and/or the VVP with or without reflux to the transverse, sigmoid, inferior petrosal, or cavernous sinus; Type 2, dominant retrograde drainage to the cavernous sinus and/or orbital veins with or without anterograde drainage to the IJV and/or VVP or cortical venous reflux; and Type 3, dominant or exclusive venous drainage to cerebellar pial or perimedullary veins (Fig. 2). All HCDAVFs were grouped into these 3 types of venous drainage based on available images and/or angiographic descriptions by the senior author.

\section{Statistical Analysis}

The significance of differences in frequency of clinical presentation patterns across the three groups of venous drainage was assessed using stratified exact logistic regression, with single publications as strata (Stata version 12.1, StataCorp LP). All papers contributing only one case were combined in one stratum. Only if the overall comparison of all groups was significant were pairwise comparisons performed. For all group comparisons, $p$ values $\leq 0.05$ were considered as statistically significant. Likewise, differences were also analyzed for the therapeutic outcome (angiographic occlusion, clinical cure, and per- manent morbidity) across the 4 major treatment modalities (endovascular treatment [EVT], surgery, radiotherapy, and conservative) and the 3 EVT subgroups (TVE including combined transarterial embolization [TAE] and TVE procedures, TAE using liquid embolic agents, and TAE procedures with other agents). Cases in which clinical and/or angiographic outcomes were not reported were excluded from the respective analysis of outcome.

\section{Results}

\section{Literature Review Results}

Results of the literature review process are illustrated in Appendix Fig. 1. One hundred thirteen cases of HCDAVF in the literature have been described mainly in case reports (21 articles), smaller case series (16 articles) with the largest series comprising 14 cases, ${ }^{47}$ or as part of series comprising different types of DAVFs (11 articles). After further inclusion of 7 personal cases, a total of 120 HCDAVFs were identified.

\section{Presentation and Clinical Findings}

Table 1 summarizes the clinical presentation and venous drainage patterns of all HCDAVFs. The individual details from all reviewed cases are summarized in Appendix Table 4.

By and large, patients presented with pulse-synchronous tinnitus (PT; $75 \%$ of all fistulas), which could be explained by direct transmission of the venous bruit to the inner ear through the temporal bone. PT was often the only symptom in HCDAVFs with solely anterograde venous drainage (Type 1), ${ }^{1,45}$ or it was found in addition to other of the below-mentioned symptoms. PT showed a significant association with venous drainage Types 1 and 2 (Type 1 vs 3: $p<0.0001$, Type 2 vs 3: $p<0.0001$ ) and did not occur in venous drainage Type 3 HCDAVFs. Headache was another commonly encountered but nonspecific symptom.

Orbital symptoms (chemosis, proptosis, and/or diplopia from oculomotor or abducens nerve palsies) due to reflux into the cavernous sinus and SOV (by way of the IPS and ICAVP) were the second most frequent clinical presentations (30.8\% of HCDAVFs). 2,10,12,13,23,31,36,51,69,75,81,82 They reached a prevalence of $100 \%$ in the venous drainage Type 2 (Fig. 3) and were rather infrequent in the other venous drainage types $(\mathrm{p}<0.0001$ for Type 1 vs 2 and Type 3 vs 2 ). In these instances, symptoms were indistinguishable from those of cavernous sinus fistulas. Mironov et al. reported the case of an HCDAVF that caused ipsilateral tinnitus and contralateral orbital symptoms due to retrograde drainage into the contralateral cavernous sinus and/ or SOV via the intercavernous sinus. ${ }^{50}$

Hypoglossal canal DAVFs may occasionally present with hypoglossal nerve palsy or involuntary tongue movements (11.7\% of HCDAVFs) related to pulsatile compression and venous hypertension from a dilated ACV within the hypoglossal canal.6,13,39,52,71 Hypoglossal nerve palsy was present only in venous drainage Type 1 HCDAVFs, and its prevalence there (18.7\%) was significantly higher than in venous drainage Type 2 HCDAVFs $(\mathrm{p}=0.0089)$. In $50 \%$ (7 of 14) of these fistulas, retrograde venous drain- 

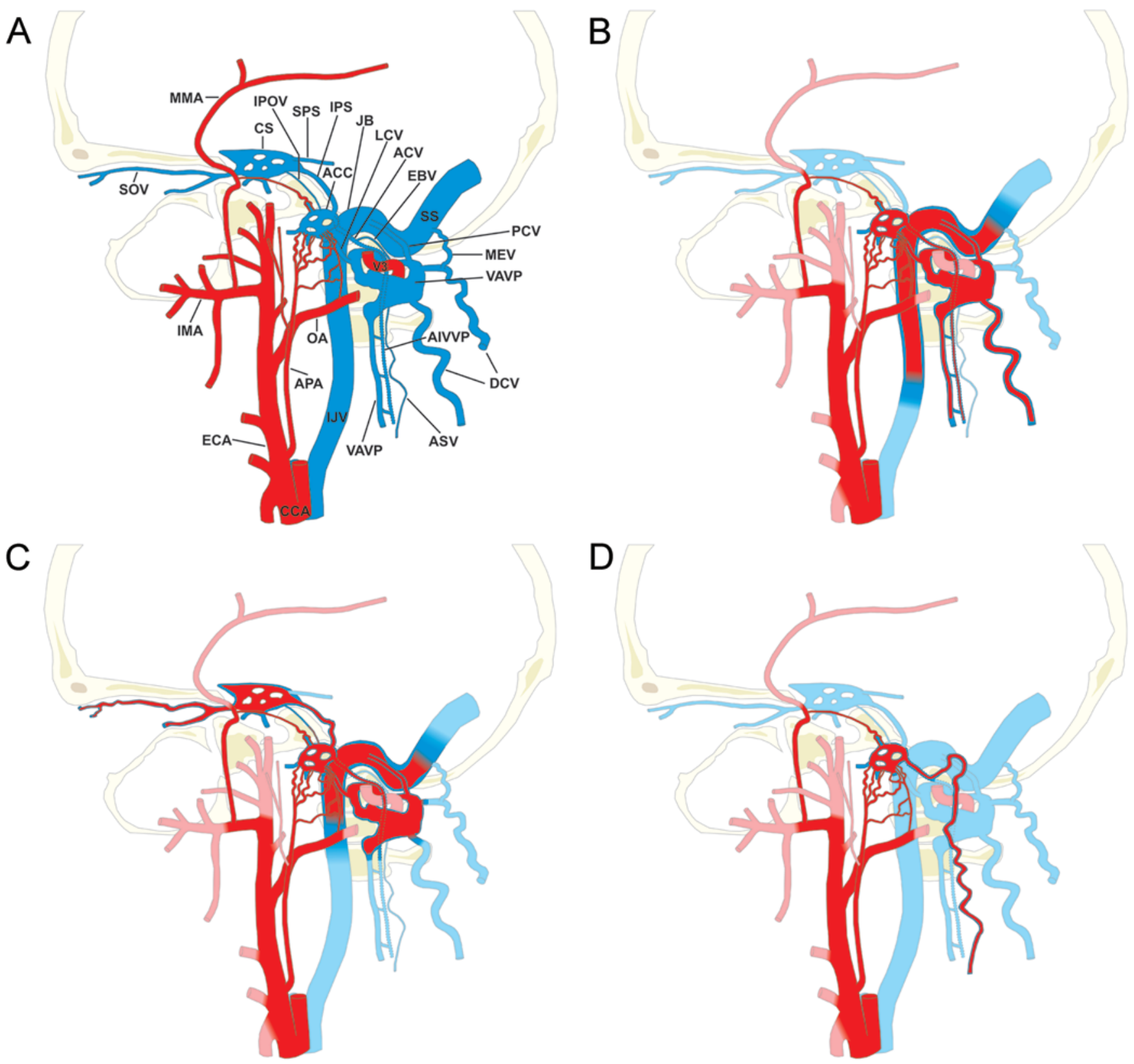

FIG. 2. Illustrations of HCDAVFs with the fistula points at the ACC (lateral view). A: Arterial feeders are depicted from the neuromeningeal division of the ascending pharyngeal artery (APA), petrous branch of the middle meningeal artery (MMA), and the mastoid branch of the occipital artery (OA). Variable venous connections of ACC and condylar veins with possible venous drainage routes are also depicted. Three major types of venous drainage: Type 1 (B), dominant anterograde venous drainage to the VVP/vertebral veins via condylar veins and to the IJV with reflux into sigmoid/transverse sinus; Type 2 (C), dominant retrograde drainage to the IPS/cavernous sinus/SOV with anterograde venous drainage to the IJV/VVP and sigmoid/transverse sinus; and Type $3(\mathrm{D})$, exclusive perimedullary drainage via the emissary bridging vein to the anterior medullary vein/anterior spinal vein. Dotted vessel margins of the ACV and AIVVP indicate the medial location relative to the jugular venous system and VAVPS. APA = ascending pharyngeal artery; $A S V=$ anterior spinal vein; $C C A=$ common carotid artery; $C S=$ cavernous sinus; $D C V=$ deep cervical vein; EBV = emissary bridging vein; ECA = external carotid artery; IMA = internal maxillary artery; IPOV = inferior petrooccipital vein; JB = jugular bulb; MMA = middle meningeal artery; OA = occipital artery; SPS = superior petrosal sinus; SS = sigmoid sinus; V3 $=$ V3 segment. Copyright Björn Spittau. Published with permission.

age to the ipsilateral IPS was present; one of them showed additional venous reflux to the transverse, sigmoid, and bilateral cavernous sinuses. No orbital or cortical venous reflux was identified in these fistulas.

Intracranial hemorrhage was encountered in only 6 cases ( $5 \%$ of HCDAVFs), 4 presenting with posterior fossa subarachnoid hemorrhage and 1 with cerebellar intraparenchymal hemorrhage. In these cases, venous drainage occurred exclusively toward the pial posterior fossa veins $^{24,28,47,62}$ and/or into the perimedullary and/or peri- 
TABLE 1. Clinical presentation of 120 HCDAVFs

\begin{tabular}{|c|c|c|c|c|c|c|}
\hline Factor & $\begin{array}{c}\% \text { of Cases } \\
\text { (no.) }\end{array}$ & PT/Bruit & $\begin{array}{c}\text { Orbital } \\
\text { Symptoms }\end{array}$ & $\begin{array}{l}\text { Hypoglossal } \\
\text { Nerve Palsy }\end{array}$ & Myelopathy & $\begin{array}{l}\text { Intracerebral } \\
\text { Hemorrhage }\end{array}$ \\
\hline \multicolumn{7}{|l|}{ Dominant venous drainage (no. of cases) } \\
\hline Type 1: anterograde & $62.5(75)$ & $92 \%(69) \dagger$ & $12 \%(9)$ & $18.7 \%(14)^{*}$ & $2.7 \%(2)$ & $0 \%(0)$ \\
\hline Type 2: retrograde orbital & $23.3(28)$ & $75 \%(21) \ddagger$ & $100 \%(28)^{\star} \ddagger$ & $0 \%(0)$ & $0 \%(0)$ & $0 \%(0)$ \\
\hline Type 3: pial or perimedullary & $14.2(17)$ & $0 \%(0)$ & $0 \%(0)$ & $0 \%(0)$ & $64.7 \%(11) \dagger \ddagger$ & $35.3 \%(6) \dagger \ddagger$ \\
\hline Global difference in venous drainage, $p$ value $\S$ & & $<0.0001$ & $<0.0001$ & 0.0029 & 0.0001 & 0.0003 \\
\hline Total (no. of cases) & $100(120)$ & $75 \%(90)$ & $30.8 \%(37)$ & $11.7 \%(14)$ & $10.8 \%(13)$ & $5 \%(6)$ \\
\hline
\end{tabular}

† Significant differences in clinical presentation for pairwise group comparisons between venous drainage Types 1 versus 3 .

* Significant differences in clinical presentation for pairwise group comparisons between venous drainage Types 1 versus 2 .

‡ Significant differences in clinical presentation for pairwise group comparisons between venous drainage Types 2 versus 3 .

$\S$ Refers to a global test of group differences in clinical presentation between all three types of venous drainage.

spinal veins. , $24,28,62$ Hence, the prevalence of hemorrhage was significantly more frequent in HCDAVFs with venous drainage Type 3 versus Types 1 and 2 ( $\mathrm{p}=0.0013$ and 0.0195 , respectively). Venous drainage Type 3 HCDAVFs may also produce symptoms related to cervical myelopathy due to perimedullary venous hypertension $(10.8 \%$ of HCDAVFs). $3,11,13,18,25,26,46,47,69,79$ The prevalence of myelopathy in Type 3 HCDAVFs was significantly more common than in Types 1 and $2(p=0.0046$ and 0.0004 , respectively).

Other rare clinical symptoms included dizziness, otalgia and/or ear fullness, and facial nerve palsy $(4.2 \%$ of HCDAVFs). ${ }^{12,13,27}$ As in DAVFs in other locations, symptoms may change occasionally in relation to spontaneous occlusion of one draining pathway, after partial fistula occlusion, or because of high-flow vasculopathy with draining vein stenosis. In such instances, the redirection of flow to another draining route may result in the disappearance of PT or the subsequent development of ocular symptoms, hypoglossal nerve palsy, or even congestive myelopathy. ${ }^{13,17,39,52,73}$ Rarely, Type 1 HCDAVFs may be asymptomatic. 32

\section{Imaging Findings and Angiographic Anatomy}

Distinguishing HCDAVF from other skull base DAVFs, such as posterior condylar canal or inferior petroclival vein fistulas, ${ }^{30,66}$ may be challenging and implies a thorough knowledge of the complex venous anatomy. The radiological hallmark of HCDAVF is the presence of an arterialized $\mathrm{ACC}$ and/or ACV representing the fistulous point. However, HCDAVFs may be difficult to visualize radiologically. Indeed, several previously reported DAVFs, which could very likely be classified as HCDAVF, were often described on conventional digital subtraction angiography (DSA) as being located at the skull base, foramen magnum, craniocervical junction, jugular foramen, jugular bulb, IPS, or marginal sinus. ${ }^{5,6,9,11,12,23,24,26,28,37,42,44,46,47,50,60,62,71,73,78,81,82}$

Cross-sectional imaging techniques aim at demonstrating an arterialized ACC and/or ACV, a venous pouch corresponding to a dilated ACC and/or ACV, dilated and tortuous pial or perimedullary veins, and intraosseous fistula components. The latter may exist within the lower clivus and/or occipital condyle around the hypoglossal canal, on the medial wall of the jugular bulb, within the jugular process, within jugular tubercle of the occipital bone, and around the opening of the posterior condylar canal. ${ }^{29,42,71}$ Arterialized veins may be demonstrated on CT angiography $(\mathrm{CTA})^{48}$ if the image is obtained during the early arterial phase, and CTA may show conspicuous filling of the HCDAVF. Subtracted dynamic whole-head CTA using a multi-row (320) detector scanner overcomes limitations due to partial volume with bone and provides hemodynamic information similar to DSA (Videos 1 and 2). ${ }^{80}$

VIDEO 1. Dynamic CTA study acquired using a 320-row detector scanner (Aquilion ONE, Toshiba) from a 52-year-old patient with Type 1 HCDAVF who presented with PT only. The images are targeted on the right cranial carotid circulation and displayed in $360^{\circ}$ rotational views. Early filling of the right $A C C$ and ACV with venous reflux into the IPS and posterior cavernous sinus, sparing the SOV, is depicted. Timely filling of the right sigmoid sinus is also visible. Copyright Stephan Meckel. Published with permission. Click here to view with Media Player. Click here to view with Quicktime.

VIDEO 2. Targeted images on the right cranial carotid circulation, lateral view, from the same study in Video 1. Hemodynamics of a Type 1 HCDAVF with retrograde venous flow to the IPS and cavernous sinus, sparing the SOV, is demonstrated. Copyright Stephan Meckel. Published with permission. Click here to view with Media Player. Click here to view with Quicktime.

Standard MRI is not sensitive in detecting DAVFs and may fail to demonstrate an HCDAVF entirely (Fig. 4). Rarely, an HCDAVF can mimic a hypervascular skull base tumor on standard MRI ${ }^{39}$ Source images of timeof-flight (TOF) magnetic resonance angiography (MRA) generally detect the arterialized ACC and/or ACV as well as the precise anatomical localization of the venous pouch. 1,13,15,17,27,31,45,69 However, low-grade HCDAVFs can remain undetected, and false-positive results can occur because of retrograde flow-related signal in the skull base veins, in particular, in the IPS. ${ }^{56}$ Dynamic 4D MRA techniques may represent, as with lesions in other locations, a valuable additional tool, as they provide information similar to DSA, although the lower spatial and temporal resolutions may fail to demonstrate the exact angiographic characterization of HCDAVFs, in particular, in low-grade fistulas. ${ }^{49,54}$

In some cases, expansion of the hypoglossal canal may be observed as a valuable indirect sign on CT. ${ }^{13,45}$ The intraosseous fistula components, which correspond to dilated diploic veins, may be well demonstrated on MRI, particularly with postcontrast 3D T1-weighted MRI and 3D TOF MRA. ${ }^{10,17,27}$ 

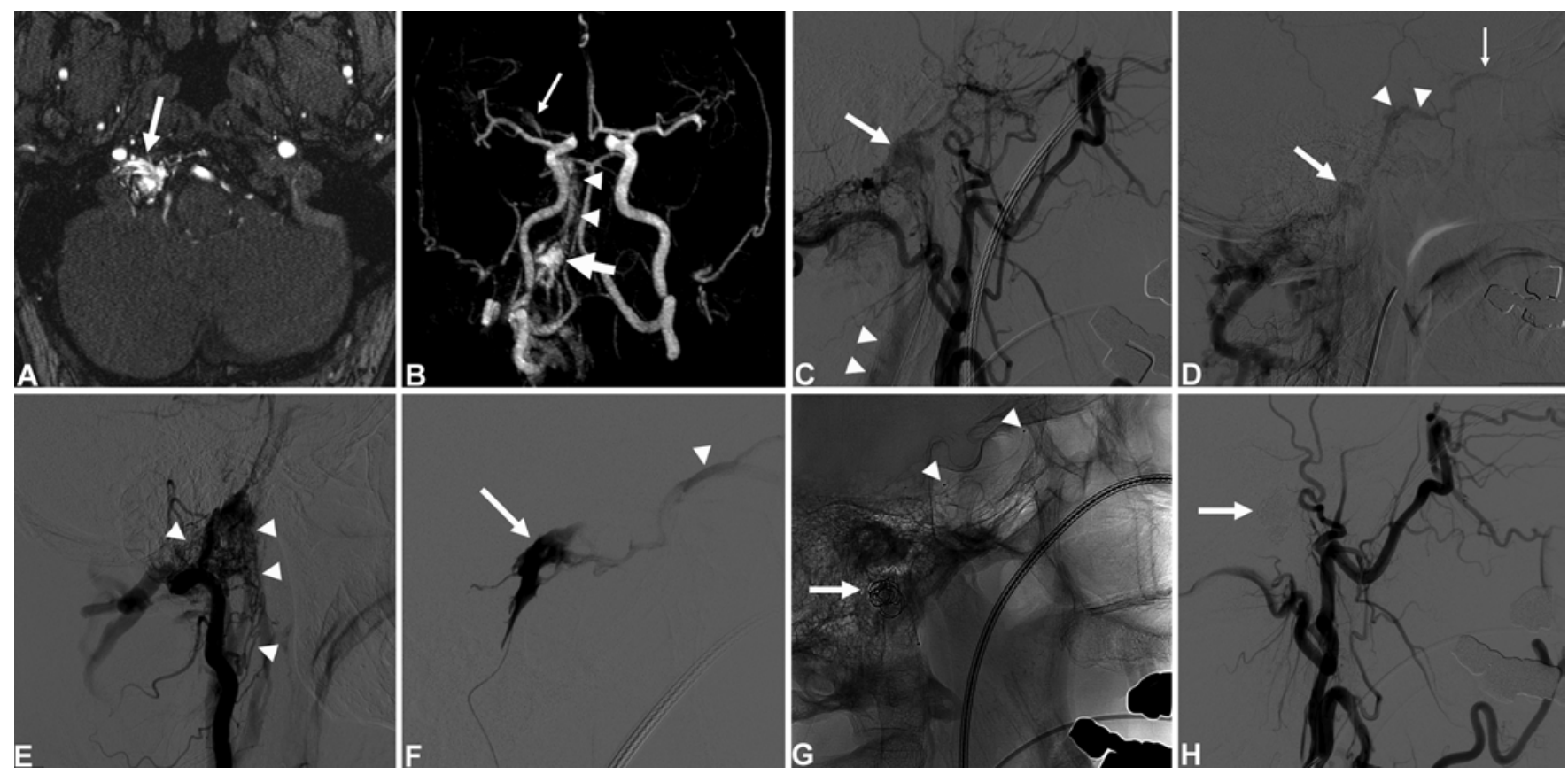

FIG. 3. Images obtained in a 50-year-old man with progressive right PT, diplopia, chemosis, and proptosis of the right eye, as well as tongue deviation. Time-of-flight MRA source image shows a venous pouch within the right hypoglossal canal (arrow, A) with surrounding hyperintense vessels of the ACC. Coronal oblique maximum-intensity projection (MIP) image of contrast-enhanced 4D MRA shows arterial filling of the venous pouch (thick arrow, B) and retrograde venous flow through the IPS and cavernous sinus (arrowheads) into the SOV (thin arrow). Digital subtraction angiograms (C-E) confirm a DAVF with a venous pouch within the hypoglossal canal (arrows in $\mathbf{C}$ and $\mathbf{D}$, right ECA injections) and also show angiographic architecture with feeders from the ipsilateral occipital, ascending pharyngeal (not shown), middle meningeal, and distal internal maxillary arteries, as well as numerous small branches of the VA (arrowheads in E, right VA injection). In addition, little supply originating from the contralateral ascending pharyngeal artery and VAs was seen (not shown). Note the anterograde venous drainage via several venous channels into the IJV (arrowheads in C). A guide catheter was placed in the upper IJV, while microwire enters the venous channel to the fistula pouch. On a later-phase image, fistula reflux into the IPS is seen, with the cavernous sinus (arrowheads in D) reaching the SOV (thin arrow in D). In addition, the fistula drains anterogradely via the condylar veins to the vertebral and suboccipital venous plexus. A microcatheter system (Excelsior SL-10, Transend EX 14 [Boston Scientific]) was used to pass through the fistulous pouch and IPS to access the right cavernous sinus (arrow in F). Superselective injection shows fistula reflux to the SOV (arrowhead in F). A second microcatheter system (Excelsior 1018, Synchro 14 [Boston Scientific]) was then introduced into the fistula pouch for subsequent coil embolization using soft coils to minimize pressure on the hypoglossal nerve. Unsubtracted image during coiling demonstrates the first coil placed inside the venous pouch (arrow in $\mathbf{G}$ ). During coiling, the first microcatheter was left in the cavernous sinus (arrowheads in G) as rescue access in case of a potential residual fistula or re-routed upstream flow. Final angiogram (H) obtained after coil occlusion of the hypoglossal pouch (arrow), showing complete DAVF occlusion. At this point, the first microcatheter was removed. On a follow-up visit 1 month later, symptoms had disappeared. Follow-up MRA after 5 months showed no residual DAVF.

Conventional DSA, especially if coupled with 3D rotational angiography and C-arm cone-beam CT imaging, remains the gold standard for depicting the fistulous location, the arterial supply, and the venous drainage routes of an HCDAVF. Furthermore, DSA allows for the assessment of arterial and venous access to the fistulous point. All of these factors are indispensable for planning treatment. In particular, source images from 3D DSA techniques allow for the precise localization of fistulous points and drainage pathways including draining vein stenosis in relation to bony structures of the skull base. ${ }^{13,27,36,52}$ The arterial supply of an HCDAVF derives in particular from the neuromeningeal division of the ascending pharyngeal artery (92\% of HCDAVFs) and the transmastoid branches of the occipital artery (56.3\%) supplemented by meningeal VA branches of the V3 and V4 segments (47.3\%) and clival branches of the meningohypophyseal trunk (21.4\%), which oftentimes may be bilateral. ${ }^{47}$ Less frequently, branches from the posterior auricular (13.4\%), middle meningeal
(14.3\%), accessory meningeal, and internal maxillary (5.4\%) arteries may contribute. Angiographically, this rich network of arterial supply may produce the erroneous impression of a wide area of fistulous involvement rather than a focal location at the ACC or ACV. In this respect, contralateral carotid artery injections as well as supraselective microcatheter injections may be particularly useful to precisely delineate the fistulous point without overlapping crowded vasculature. . $^{13,17,31}$

\section{Venous Drainage Pathways}

Owing to the rich network of connections of the ACC and ACV, HCDAVFs may display complex venous drainage patterns. ${ }^{12,13,45,64}$ In most fistulas (62.5\%), venous drainage Type 1 to the jugular bulb and IJV and/or the VVP was observed. In contrast, $23.3 \%$ of HCDAVFs showed retrograde orbital venous drainage (Type 2; Fig. 3) correlating with orbital symptoms (see Presentation and Clinical Findings). Some fistulas with reflux only to the IPS 

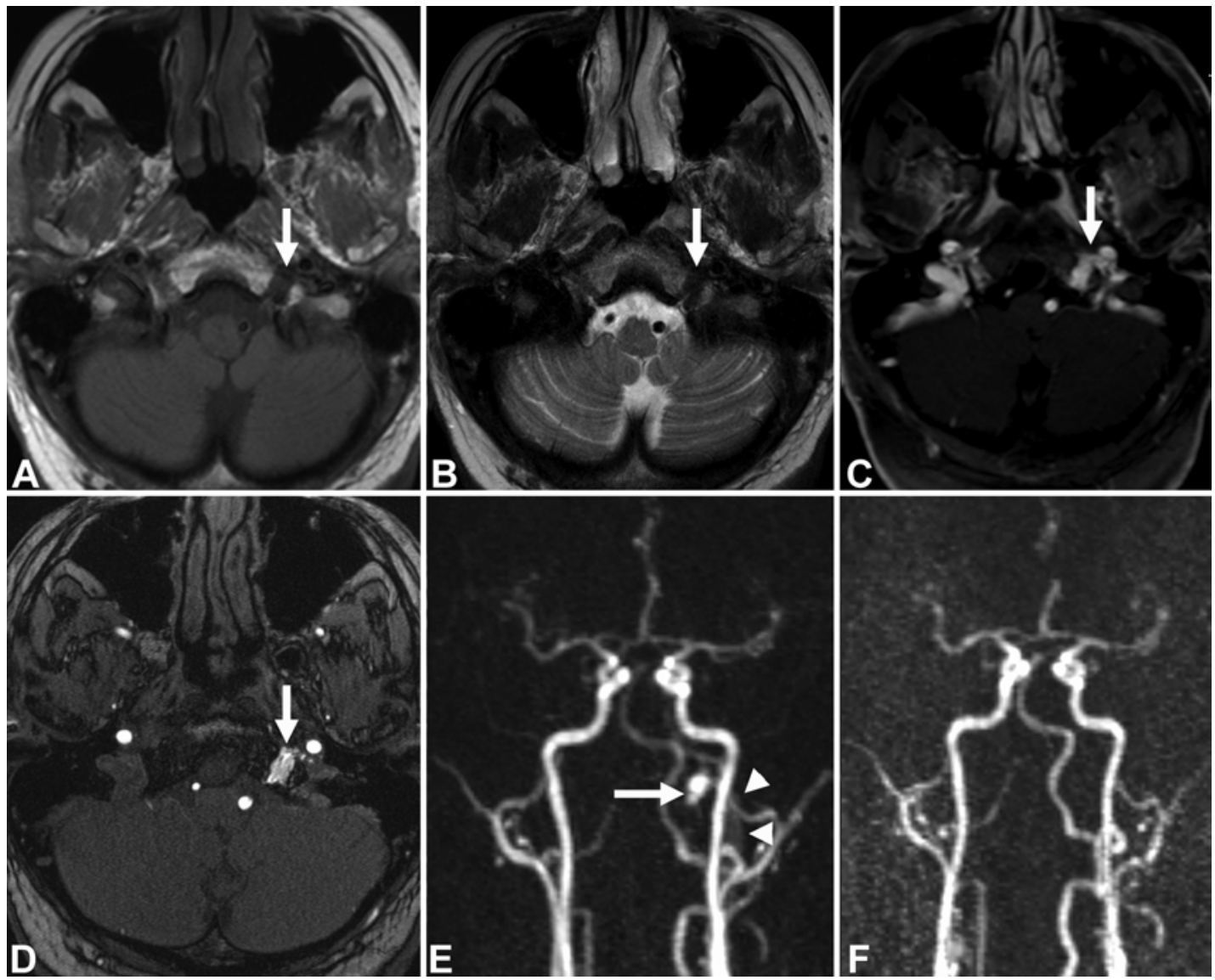

FIG. 4. Images obtained in a 65-year-old patient presenting with dysarthria, dysphagia, tongue deviation and left nuchal weakness, and PT. Conventional T1-weighted (A), T2-weighted (B), and T1-weighted post-Gd with fat saturation (C) MR images do not reveal clear signal abnormality except for subtle asymmetrical venous contrast enhancement within the left hypoglossal canal (arrows). TOF MRA (D) shows abnormal flow signal (arrow) within the left hypoglossal canal without intracranial or extracranial extension. Correspondingly, dynamic 4D contrast-enhanced MRA study (E) shows early enhancement of hypoglossal canal (medial to jugular bulb, arrow) during the arterial phase with faint opacification of the left IJV (arrowheads). Clinically, spontaneous, complete resolution of symptoms was observed 12 months after initial presentation. On a follow-up MRA study after 15 months (F), the absence of early venous filling at the hypoglossal canal because of fistula occlusion is visible.

and the cavernous sinus did not necessarily present with orbital symptoms. Anatomical variation, very high flow HCDAVFs, outflow venous stenosis of the connections to the VVP or IJV, or thrombosis may result in dominant retrograde Type 2 drainage. $5,13,38,50,51,75,82$ Rarely, contralateral cavernous sinus and/or SOV drainage via the intercavernous plexus ${ }^{2,12,50}$ or drainage to the contralateral IJV via a prevertebral anastomosis in between both ACCs (Fig. 5) may be observed. Retrograde flow to the transverse and/ or sigmoid sinuses was observed in $8.3 \%$ of HCDAVFs, as well as into the superficial middle cerebral veins and superior petrosal sinuses by way of the cavernous sinus and IPS in $1.7 \%$ and in $0.8 \%$ of HCDAVFs, respectively. ${ }^{31}$ Retrograde cortical venous drainage was observed in $13.3 \%$ of HCDAVFs, $2,12,17,24,27,47,51,62$ often seen in combination with retrograde orbital drainage (Type 2) and partially associated with orbital symptoms without intracranial hemorrhage. Exclusive cortical or perimedullary (Type 3) venous drainage was observed in $14.2 \%$ of HCDAVFs that presented with either intracranial hemorrhage ${ }^{24,28,47,62}$ or cervical myelopathy 3,11,18,25,26,46,47,69,79 (see Presentation and Clinical Findings). These fistulas were located on the in- tracranial ACV portion and drained directly into the pontomesencephalic veins by way of the emissary bridging veins with subsequent ascending (toward the cerebellar pial or petrosal veins) or descending (to the anterior and/ or posterior spinal veins) perimedullary venous drainage. In these cases, no demonstrable anastomosis between the $\mathrm{ACV}$ and the IPS, IJV, or VVP was seen, probably because of the thrombosis. ${ }^{69}$ By contrast, thrombosis may also develop within the perimedullary drainage route with subsequent cord infarction and rerouting of drainage toward the VVP or the IPS and cavernous sinus. ${ }^{73}$ Choi et al. reported a case of HCDAVF with high-grade stenosis at the connection between the ACC and IJV, which resulted in perimedullary spinal drainage in the absence of other draining routes from the ACV. ${ }^{13}$ In most Type 3 HCDAVFs presenting with myelopathy, MRI of the cervical spine revealed brainstem and upper spinal cord edema. Further, MRI may also show abnormal engorged perimedullary spinal veins with or without thrombosis, contrast enhancement of the spinal cord, or even medullary compression by focal venous ectasia. ${ }^{3,11,13,18,25,26,46,59,69}$ 


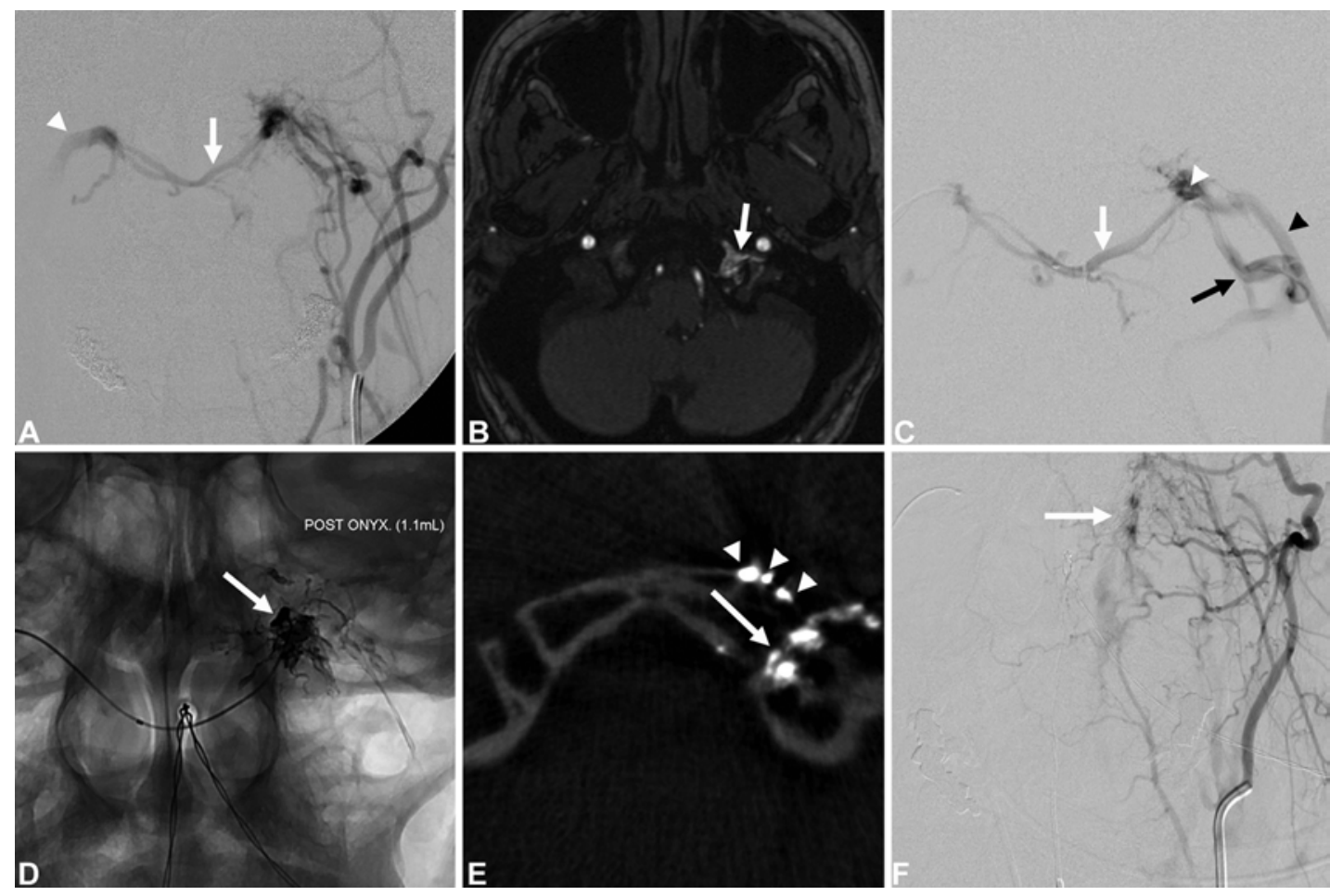

FIG. 5. Images obtained in a 41-year-old patient with a 2-year history of PT. DSA image (A) reveals a left HCDAVF supplied by the medial clival branches of the left ICA (not shown) and neuromeningeal division of the left ascending pharyngeal artery and left occipital artery branches. Venous drainage is anterograde to the left IJV and/or condylar veins and retrograde via the prominent prevertebral vein at C-1 connecting midline (arrow) to the contralateral ACC and then to the right IJV (arrowhead). TOF MRA source image (B) depicts a venous pouch within the hypoglossal canal (arrow) and adjacent ACC. TVE was performed with a 0.010-in Onyx-compatible microcatheter navigated from the right ACC through the prevertebral vein (white arrow in C) into the fistulous pouch at the left ACC (white arrowhead in C, showing the microcatheter tip inside the fistulous pouch). Superselective pouch injection also demonstrates ipsilateral drainage to the left IJV (black arrowhead in C) and LCV (black arrow in C). Onyx-18 was slowly injected over approximately 30 minutes until backfilling into the suboccipital veins and arterial feeders from the ascending pharyngeal and clival arteries (arrow in D showing outline of the Onyx cast). Flat-panel CT (E) demonstrates Onyx distribution within the left ACV (arrow), ACC, and prevertebral vein (arrowheads). Final occipital (F) and ascending pharyngeal artery (not shown) angiograms disclose mild residual fistula filling (arrow).

\section{Therapeutic Management of HCDAVFs}

The therapeutic management, outcome, and morbidity of all HCDAVFs are summarized in Table 2. The individual details from all reviewed cases are summarized in Appendix Table 5. Treatment was performed in $92.5 \%$ of HCDAVFs. Treatment was rendered if a high-grade fistula with orbital, cortical, or perimedullary venous reflux was present ${ }^{75}$ or in cases of intolerable PT. Moreover, 76.7\% of HCDAVFs were treated with EVT, whereas the others were treated using surgery, including combinations with EVT and/or radiosurgery (12.5\%) and radiotherapy or stereotactic radiosurgery with or without EVT (3.3\%). Given the small size of the latter two groups and the comparable outcomes among the four major treatment groups (EVT, surgery, radiotherapy, and conservative), no significant differences between the four treatment modalities were demonstrated. Overall, EVT resulted in $93.4 \%$ angiographic fistula obliteration, 5.4\% permanent morbidity, and $0 \%$ mortality. Among the patients with EVT, the majority was treated with TVE (56.7\% of HCDAVFs), of which $75 \%$ involved TVE exclusively and $25 \%$ involved combined TAE and TVE procedures. Other EVT procedures included TAE with liquid embolic agents (15\%), TAE with other agents (4.2\%), and 1 case (0.8\%) of nonspecified EVT. Again, among these EVT subgroups, no significant difference in outcomes was observed. In the EVT groups, angiographic occlusion rates varied between $80 \%$ and $94.4 \%$, clinical cure rates between $58.8 \%$ and $91 \%$, and permanent morbidity between $2.9 \%$ and $16.7 \%$.

TVE led to the highest rate of clinical cure (91\%) at a relatively low therapeutic risk (permanent morbidity $2.9 \%$ ). The most direct route for TVE of an HCDAVF is trans-IJV access. In some cases, however, a transvenous approach via the ipsilateral IJV may be impossible because of occluded or extremely small and tortuous connecting veins to the venous pouch. In such cases, a crossover transvenous route through the contralateral IJV and IPS, intercavernous sinus, and ipsilateral cavernous sinus and IPS to the recipient fistulous pouch may be feasible. ${ }^{12,44,47}$ Contralateral IJV access can also be achieved through prevertebral connections between both ACCs (Fig. 5). Alternatively, TVE may also be possible via the VVP or the SOV following direct surgical access. ${ }^{12,23,34,36,45,51,69}$ In the majority of TVEs, coils were used to obliterate the fistulous venous pouch at the ACC and/or the ACV (92.7\%). Other embolic materials used in TVE were Onyx (2.9\%), Onyx and coils (2.9\%), and silk and coils $(1.5 \%)$. 
TABLE 2. Treatment, outcome, and permanent morbidity in 120 HCDAVFs

\begin{tabular}{|c|c|c|c|c|}
\hline Treatment Modality & No. of HCDAVFs (\%) & $\begin{array}{c}\% \text { w/ Angiographic } \\
\text { Occlusion (no. of cases) }\end{array}$ & $\begin{array}{c}\% \text { w/ Clinical Cure } \\
\text { (no. of cases) }\end{array}$ & $\begin{array}{c}\% \text { w/ Permanent Morbidity } \\
\text { (no. of cases) }\end{array}$ \\
\hline Total EVT† & $92(76.7)$ & $93.4(85 / 91)$ & $83.2(74 / 89)$ & $5.4(5 / 92)$ \\
\hline TVE* & $68(56.7)$ & $92.7(63 / 68)$ & $91(61 / 67)$ & $2.9(2 / 68)$ \\
\hline TAE w/ liquid embolic agents & $18(15)$ & $94.4(17 / 18)$ & $58.8(10 / 17)$ & $16.7(3)$ \\
\hline TAE w/ other agentsł & $5(4.2)$ & $80.0(4 / 5)$ & $60(3 / 5)$ & 0 \\
\hline Surgery§ & $15(12.5)$ & $90(9 / 10)$ & $73.3(11 / 15)$ & $13.3(2)$ \\
\hline Radiotherapy§ & $4(3.3)$ & $100(3 / 3)$ & $33.3(1 / 3)$ & 0 \\
\hline No treatment & $9(7.5)$ & $100(7 / 7)$ & $87.5(7 / 8)$ & NA \\
\hline \multicolumn{5}{|c|}{$\begin{array}{l}\text { NA = not applicable. } \\
\dagger \text { Includes combined therapies of TVE and TAE with different embolic agents. } \\
\text { * Includes one case of unspecified EVT. } \\
\ddagger \text { Includes all nonliquid embolic agents (for example, PVA, silk) and unspecified TAE. } \\
\S \text { Includes combinations of surgery or radiotherapy with other modalities (for example, TAE). }\end{array}$} \\
\hline
\end{tabular}

In three reports, TVE of an HCDAVF was complicated by transient ( 2 cases) and permanent (1 case) hypoglossal nerve palsy after coil embolization of the fistulous pouch, ${ }^{45,47,52}$ presumably due to mass effect from coils on the hypoglossal nerve. Some authors have recommended using soft rather than stiff coils and avoiding tight packing and/or overpacking with coils to reduce the risk of hypoglossal nerve palsy. ${ }^{45,52}$ In addition, precise localization of the shunting point by superselective $3 \mathrm{D}$ rotational DSA may enable placing the coils into the ACC rather than within the constrained hypoglossal canal. ${ }^{45,52}$ Three patients developed dural venous sinus thrombosis (1 asymptomatic; 2 with transient and permanent morbidity, respectively) following TVE procedures with coils and silk and with Onyx, presumably due to reflux of the embolic agents into the jugular bulb. ${ }^{5}$ In TVE with coils, a double microcatheter technique, in which one microcatheter is placed distally into the cavernous sinus and/or the IPS and another one is placed proximally into the venous pouch, may be advantageous (Fig. 3). The distal microcatheter may serve as a rescue access to the fistula in case the proximal microcatheter kicks back proximally or in case of residual fistula flow distally after coil occlusion proximally at the ACC. ${ }^{67,74}$ Recently, Takemoto et al. presented a series of 3 HCDAVFs that had been treated transvenously using Onyx combined with coils (2 lesions) or with Onyx only (1 lesion) injected into the recipient fistulous pouch. ${ }^{68}$ These authors achieved complete fistula occlusion in all cases and observed a transient hypoglossal palsy in 1 case. This approach is potentially advantageous because overpacking with dense coils, leading to undesirable hypoglossal nerve palsy, may be avoided because of the nonadhesive and cohesive properties of Onyx, as in cavernous sinus fistulas. ${ }^{67,68}$ However, potential complications include direct neurotoxicity of the dimethyl sulfoxide solvent (for example, trigeminocardiac reflex) and retrograde arterial embolization of Onyx into the vasa nervorum supplying a cranial nerve. ${ }^{21,40,68}$

Transarterial embolization using polyvinyl alcohol (PVA) particles was generally not considered a primary treatment modality because of a higher tendency for fistula recurrence, although it may serve to reduce fistula flow. ${ }^{13,17,36,42,45,47,81}$ Transarterial embolization using liquid embolic agents such as $N$-butyl cyanoacrylate (NBCA) or Onyx is indicated in cases of Type 3 HCDAVFs with exclusive cortical and/or perimedullary venous drainage or when transvenous access to the fistulous site is not possible. ${ }^{911,18,25,47,62,69,79}$ However, TAE with liquid embolic agents carries a significant risk of lower cranial nerve palsies, as HCDAVFs are commonly supplied by the neuromeningeal division of the ascending pharyngeal artery, which also supplies the vasa nervorum of cranial nerves IX, X, XI, and XII..$^{9,22,33,45,65}$ Moreover, the dangerous anastomosis between the ascending pharyngeal artery and the ICA and/or VA may represent the risk of stroke in TAE. Three cases (16.7\%) of permanent morbidity with TAE using liquid embolic agents were identified: 2 hypoglossal nerve palsies following TAE with Onyx ${ }^{58}$ (Fig. 6) and 1 brainstem infarct following an NBCA injection. ${ }^{9}$

In this review, only 4 HCDAVFs were treated using surgery alone (ligation of major arterial feeders or transection at the dural exit of the vein). ${ }^{24,42,46,50}$ Combined surgical obliteration following preoperative TAE was used to treat another 8 HCDAVFs, including 5 cases with intraosseous components described by Tirakotai et al. that underwent surgical treatment via a suboccipital transcondylar approach. ${ }^{3,41,47,71}$ One case of Type 1 HCDAVF, which was mistaken for a glomus tumor, was treated using combined surgery and embolization via a far-lateral transcondylar surgical approach. ${ }^{39}$ Two recurrent intraosseous HCDAVFs were surgically treated after unsuccessful TAE and TAE plus stereotactic radiotherapy, respectively. ${ }^{42}$ Surgical complications included occipital condyle fracture with craniocervical instability and hypoglossal nerve injury in $2(13.3 \%)$ of 15 surgical cases. Earlier reports on skull base DAVFs, presumably in the location of the hypoglossal canal, have also demonstrated successful combined endovascular and surgical approaches. ${ }^{41,42}$ Despite an overall high efficacy of surgical or combined endovascular and surgical treatments for intracranial DAVFs, the risk of morbidity and mortality remains considerable (> 10\%). ${ }^{20}$ However, surgery may be indicated in cases of Type 3 HCDAVFs with eloquent or poorly accessible feeders. In such cases, the decision to treat with TAE versus surgical obliteration should be made on an individual basis after careful consideration of the clinical conditions, surgical accessibility, 

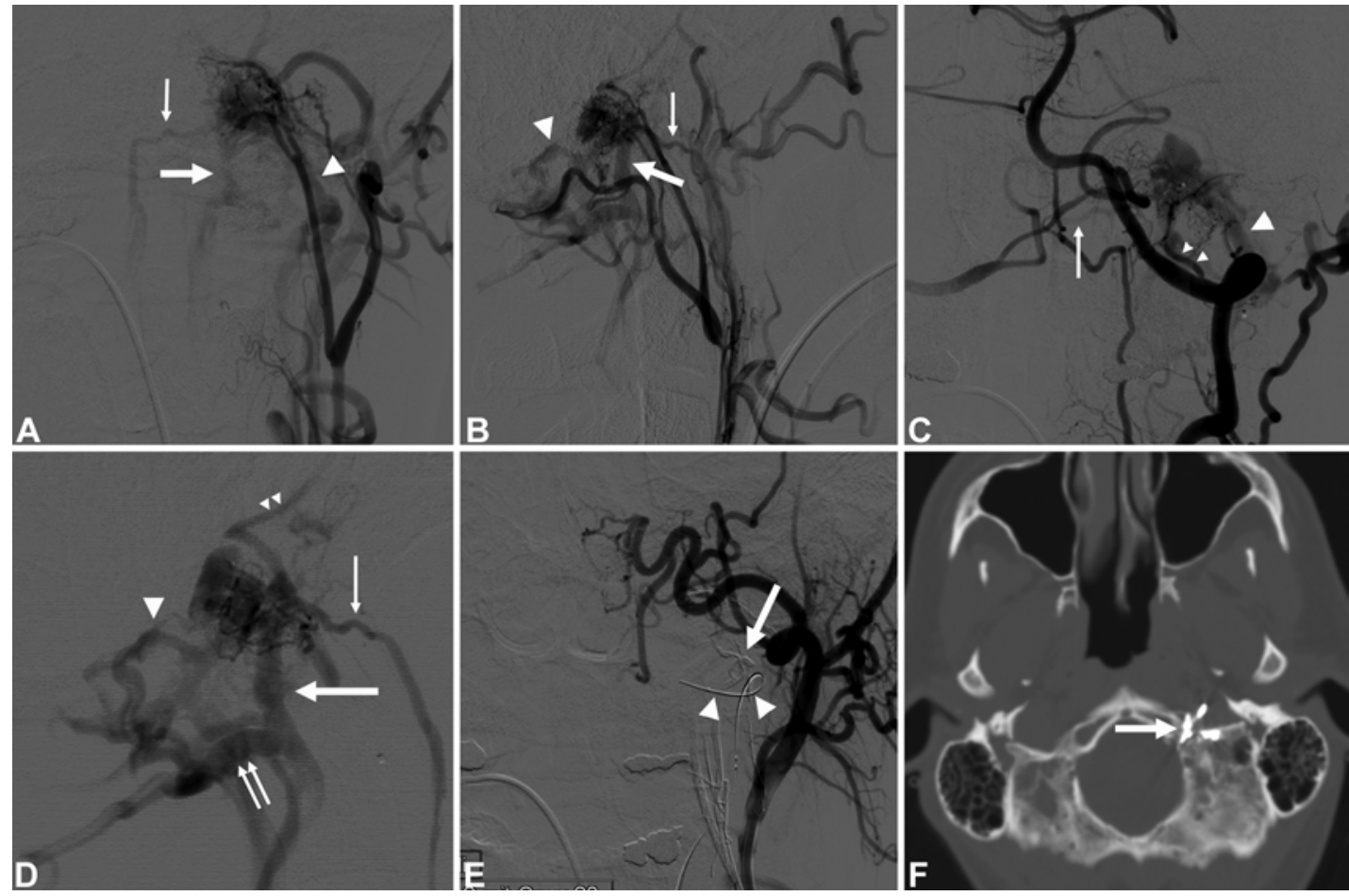

FIG. 6. Images obtained in a 46-year-old male presenting with worsening PT, neck pain, and headache. Left ECA injection DS angiograms, anteroposterior (A) and lateral (B) views, and left VA injection angiogram, anteroposterior view (C), demonstrate an HCDAVF with predominant anterograde drainage to the ACV (arrow in A), LCV (arrow in B), and PCV (large arrowheads in A-C). In addition, drainage into the branch of the pre-VVP (thin arrows in A-C) is demonstrated. The arterial supply originates from the neuromeningeal division of the ascending pharyngeal artery, small occipital artery branches, and meningeal VA branches, including the anterior meningeal artery (small double arrowheads in C). Superselective injection angiogram (D) obtained from a microcatheter wedge position within the distal ascending pharyngeal artery close to the venous pouch, demonstrating detailed anatomy of the venous drainage via the LCV (arrow) and PCV (arrowhead) with connections to the plexiform VAVP (double arrows), as well as to the pre-VVP (thin arrow) and minimal reflux into the IPS (double arrowheads). TAE using Onyx was performed from the ascending pharyngeal artery feeder, with balloon protection of the distal left VA. Postembolization left ECA injection angiogram $(\mathrm{E})$, anteroposterior view, showing fistula occlusion with Onyx cast at the fistula point (arrow) and balloon catheter guidewire (arrowheads) in the left VA. Bone-window CT image (F) obtained after embolization, demonstrating Onyx cast inside the hypoglossal canal (arrow) and at the ACC. Residual fistula flow was seen from VA feeders (not shown). Clinically, the patient developed left hypoglossal and cranial nerve X palsies and was treated with steroid boost therapy. Near-complete recovery of tongue function with atrophy was observed after 11 months. PT was completely absent, and complete HCDAVF occlusion was seen on vascular ultrasonography.

and angiographic feeding artery anatomy. Two HCDAVFs were treated with TAE using PVA followed by stereotactic radiosurgery, which resulted in only partial relief of symptoms. Complete fistula obliteration was only achieved after final $\mathrm{TVE}^{17}$ and surgery. ${ }^{37}$ In general, stereotactic radiosurgery as the sole treatment has demonstrated low obliteration rates for DAVFs. ${ }^{20,83}$ Moreover, the long latency period to achieve obliteration of the shunt in stereotactic radiosurgery is probably inappropriate for Type $3 \mathrm{HC}$ DAVFs because of the high risk of nonhemorrhagic and/ or hemorrhagic complications intrinsic to such high-grade DAVFs. Therefore, stereotactic radiosurgery should be reserved for select fistulas for which endovascular and surgical approaches have been exhausted.

Spontaneous occlusion of an HCDAVF was observed in $5.8 \%$ of cases, including 4 of 9 cases in a series by Manabe et al. ${ }^{6,45}$ In all of these cases with mostly Type 1 HCDAVFs, neurological improvement after spontaneous thrombosis was observed even though some had presented with cranial nerve palsies (Fig. 4). These cases support the benefits of a conservative strategy in low-grade HCDAVFs with subjectively tolerable symptoms (PT).

\section{Limitations of a Literature Review}

Since HCDAVFs are so rare, available data can only be obtained from published case reports or small retrospective single-center series (see Literature Review Results). Therefore, the descriptive figures for these fistulas summarizing the angiographic and clinical findings, treatment modalities, and complications are probably subject to publication bias. As a consequence, rare findings, such as hypoglossal nerve palsy at presentation, or retrograde orbital venous flow may be overrepresented in this review. On the other hand, treatment of these fistulas may occur rather infrequently in large tertiary neurointerventional centers, which may provoke a tendency to include all available cases into published case series. Moreover, some reports or book chapters briefly mention DAVFs at the skull base and/or IPS possibly in the vicinity of the hypoglossal ca- 
nal, probably representing HCDAVFs, without specifying angiographic findings, therapy, and outcome, which we thus subsequently excluded from our series. ${ }^{4,63,70}$ Other reports describe fistulas with exclusive cortical and/or perimedullary drainage located at the foramen magnum and/ or skull base without surgically or radiologically proven involvement of the ACC and/or ACV, which we also excluded from our analysis, $8,35,43,60,77$ although they probably correspond to HCDAVFs. Finally, published cases of HCDAVF may not have been detected in our literature search because they were categorized as DAVFs in another location and the publications did not provide illustrations of the cases.

\section{Conclusions}

Hypoglossal canal DAVFs are rare (approximately $3 \%-4 \%$ of cranial DAVFs) and consist of a fistulous pouch involving the ACC and/or ACV with a variable intraosseous component. Owing to the rich network of venous skull base anastomoses, HCDAVFs may display complex drainage patterns. Three major types of venous drainage are associated with distinct clinical patterns: Type 1 , dominant anterograde drainage (62.5\% of HCDAVFs), usually presents only with PT; Type 2, dominant retrograde orbital drainage (23.3\% of HCDAVFs), associated with orbital symptoms $(100 \%)$ and may clinically mimic cavernous sinus DAVF; and Type 3, exclusive pial and/or perimedullary drainage (14.2\% of HCDAVFs), presents with intracranial hemorrhage or cervical myelopathy. Hypoglossal nerve palsy was a presenting finding in $11.7 \%$ of HCDAVFs. For Type 1 and 2 HCDAVFs, TVE may be an adequate treatment, demonstrating high safety (permanent morbidity $2.9 \%$; mortality $0 \%$ ) and efficacy (angiographic occlusion 92.7\%). Understanding the complex venous anatomy is crucial for planning alternative TVE approaches if standard transjugular access is not possible. TAE and/or surgical fistula disconnection are alternative options for Type 3 HCDAVFs or if TVE is not possible. Finally, a conservative strategy may be followed in Type 1 HCDAVFs since numerous spontaneous occlusions have been described.

\section{References}

1. Abiko M, Ikawa F, Ohbayashi N, Mitsuhara T, Ichinose N, Inagawa T: Endovascular treatment for dural arteriovenous fistula of the anterior condylar confluence involving the anterior condylar vein. A report of two cases. Interv Neuroradiol 14:313-317, 2008

2. Arai Y, Ishii H, Handa Y, Ueda Y, Shirasaki N, Nozaki J, et al: Dural arteriovenous fistula within the hypoglossal canal successfully treated by transvenous embolization. Case report. Interv Neuroradiol 10:59-62, 2004

3. Asakawa H, Yanaka K, Fujita K, Marushima A, Anno I, Nose $\mathrm{T}$ : Intracranial dural arteriovenous fistula showing diffuse MR enhancement of the spinal cord: case report and review of the literature. Surg Neurol 58:251-257, 2002

4. Awad IA: Tentorial incisura and brain stem dural arteriovenous malformations, in Awad IA, Barrow DL (eds): Dural Arteriovenous Malformations. Park Ridge, IL: American Association of Neurological Surgeons, 1993, pp 131-146

5. Barnwell SL, Halbach VV, Dowd CF, Higashida RT, Hieshima GB: Dural arteriovenous fistulas involving the inferior petrosal sinus: angiographic findings in six patients. AJNR Am J Neuroradiol 11:511-516, 1990

6. Blomquist MH, Barr JD, Hurst RW: Isolated unilateral hypoglossal neuropathy caused by dural arteriovenous fistula. AJNR Am J Neuroradiol 19:951-953, 1998

7. Borden JA, Wu JK, Shucart WA: A proposed classification for spinal and cranial dural arteriovenous fistulous malformations and implications for treatment. J Neurosurg 82:166179, 1995 (Erratum in J Neurosurg 82:705-706, 1995)

8. Brunereau L, Gobin YP, Meder JF, Cognard C, Tubiana JM, Merland JJ: Intracranial dural arteriovenous fistulas with spinal venous drainage: relation between clinical presentation and angiographic findings. AJNR Am J Neuroradiol 17:1549-1554, 1996

9. Byun JS, Hwang SN, Park SW, Nam TK: Dural arteriovenous fistula of jugular foramen with subarachnoid hemorrhage: selective transarterial embolization. J Korean Neurosurg Soc 45:199-202, 2009

10. Chen CJ, Wai YY, Wang LJ, Wong YC: MRI of intraosseous dural arteriovenous malformation: findings in two cases. $\mathbf{J}$ Comput Assist Tomogr 25:133-136, 2001

11. Chng SM, Sitoh YY, Hui F: Intracranial dural arteriovenous fistula presenting with tetraparesis due to cervicomedullary junction compression. A case report. Interv Neuroradiol 10:347-351, 2004

12. Choi HS, Kim DI, Kim BM, Kim DJ, Ahn SS: Endovascular treatment of dural arteriovenous fistula involving marginal sinus with emphasis on the routes of transvenous embolization. Neuroradiology 54:163-169, 2012

13. Choi JW, Kim BM, Kim DJ, Kim DI, Suh SH, Shin NY, et al: Hypoglossal canal dural arteriovenous fistula: incidence and the relationship between symptoms and drainage pattern. Clinical article. J Neurosurg 119:955-960, 2013

14. Cognard C, Gobin YP, Pierot L, Bailly AL, Houdart E, Casasco A, et al: Cerebral dural arteriovenous fistulas: clinical and angiographic correlation with a revised classification of venous drainage. Radiology 194:671-680, 1995

15. Cyril C, Ofélia M, Hervé D: Dural arteriovenous fistula involving the anterior condylar canal. J Neuroimaging 23:425-428, 2013

16. Epstein HM, Linde HW, Crampton AR, Ciric IS, Eckenhoff JE: The vertebral venous plexus as a major cerebral venous outflow tract. Anesthesiology 32:332-337, 1970

17. Ernst R, Bulas R, Tomsick T, van Loveren H, Aziz KA: Three cases of dural arteriovenous fistula of the anterior condylar vein within the hypoglossal canal. AJNR Am J Neuroradiol 20:2016-2020, 1999

18. Ernst RJ, Gaskill-Shipley M, Tomsick TA, Hall LC, Tew JM Jr, Yeh HS: Cervical myelopathy associated with intracranial dural arteriovenous fistula: MR findings before and after treatment. AJNR Am J Neuroradiol 18:1330-1334, 1997

19. Evans AJ, Kallmes DF, Jensen ME, Dion JE: The marginal sinus normal anatomy and involvement with arteriovenous fistulae. Interv Neuroradiol 2:215-221, 1996

20. Gandhi D, Chen J, Pearl M, Huang J, Gemmete JJ, Kathuria S: Intracranial dural arteriovenous fistulas: classification, imaging findings, and treatment. AJNR Am J Neuroradiol 33:1007-1013, 2012

21. Geibprasert S, Pereira V, Krings T, Jiarakongmun P, Toulgoat F, Pongpech S, et al: Dural arteriovenous shunts: a new classification of craniospinal epidural venous anatomical bases and clinical correlations. Stroke 39:2783-2794, 2008

22. Geibprasert S, Pongpech S, Armstrong D, Krings T: Dangerous extracranial-intracranial anastomoses and supply to the cranial nerves: vessels the neurointerventionalist needs to know. AJNR Am J Neuroradiol 30:1459-1468, 2009

23. Gentric JC, Ferré JC, Raoult H, Eugène F, Gauvrit JY: Endovascular treatment of inferior petrosal sinus dural arteriovenous fistula via percutaneous puncture of the superior ophthalmic vein. J Neuroradiol 40:144-146, 2013 
24. Guo LM, Zhou HY, Xu JW, Wang GS, Tian X, Wang Y, et al: Dural arteriovenous fistula at the foramen magnum presenting with subarachnoid hemorrhage: case reports and literature review. Eur J Neurol 17:684-691, 2010

25. Hähnel S, Jansen O, Geletneky K: MR appearance of an intracranial dural arteriovenous fistula leading to cervical myelopathy. Neurology 51:1131-1135, 1998

26. Hurst RW, Bagley LJ, Scanlon M, Flamm ES: Dural arteriovenous fistulas of the craniocervical junction. Skull Base Surg 9:1-7, 1999

27. Jung C, Kwon BJ, Kwon OK, Baik SK, Han MH, Kim JE, et al: Intraosseous cranial dural arteriovenous fistula treated with transvenous embolization. AJNR Am J Neuroradiol 30:1173-1177, 2009

28. Kai Y, Hamada J, Morioka M, Ushio Y, Fujioka S: Foramen magnum dural arteriovenous fistulae with repeated subarachnoid haemorrhage. Interv Neuroradiol 4:171-176, 1998

29. Katsuta T, Rhoton AL Jr, Matsushima T: The jugular foramen: microsurgical anatomy and operative approaches. Neurosurgery 41:149-202, 1997

30. Kiyosue H, Okahara M, Sagara Y, Tanoue S, Ueda S, Mimata $\mathrm{C}$, et al: Dural arteriovenous fistula involving the posterior condylar canal. AJNR Am J Neuroradiol 28:1599-1601, 2007

31. Kiyosue H, Tanoue S, Okahara M, Mori M, Mori H: Ocular symptoms associated with a dural arteriovenous fistula involving the hypoglossal canal: selective transvenous coil embolization. Case report. J Neurosurg 94:630-632, 2001

32. Kiyosue H, Tanoue S, Okahara M, Yamashita M, Nagatomi $\mathrm{H}$, Mori H: Recurrence of dural arteriovenous fistula in another location after selective transvenous coil embolization: report of two cases. AJNR Am J Neuroradiol 23:689-692, 2002

33. Kupfer TJ, Aumann K, Laszig R, Meckel S: [Peripheral facial palsy after embolization of a dural arteriovenous fistula with Ony ${ }^{\circledR}$.] HNO 59:465-469, 2011 (Ger)

34. Kuwayama N, Akai T, Horie Y, Nishijima M, Endo S, Takaku A: Dural arteriovenous fistulae involving the transverse-sigmoid sinus and foramen magnum. Surg Neurol 41:389-395, 1994

35. Kuwayama N, Kubo M, Nishijima M, Horie Y, Endo S, Takaku A: Treatment of intracranial (dural) arteriovenous fistulas in unusual locations. Interv Neuroradiol 5 (Suppl 1): $115-120,1999$

36. Lee CY, Koh JS, Kwon GY, Ryu CW, Lee SH: Transvenous embolization of an intraosseous dural arteriovenous fistula of the anterior condylar vein with anomalous venous drainage causing ocular manifestations. J Clin Neurosci 18:413-415, 2011

37. Lewis AI, Rosenblatt SS, Tew JM Jr: Surgical management of deep-seated dural arteriovenous malformations. J Neurosurg 87:198-206, 1997

38. Liu HM, Shih HC, Huang YC, Wang YH: Posterior cranial fossa arteriovenous fistula with presenting as caroticocavernous fistula. Neuroradiology 43:405-408, 2001

39. Liu JK, Mahaney K, Barnwell SL, McMenomey SO, Delashaw JB Jr: Dural arteriovenous fistula of the anterior condylar confluence and hypoglossal canal mimicking a jugular foramen tumor. Case report. J Neurosurg 109:335-340, 2008

40. Lv X, Jiang C, Zhang J, Li Y, Wu Z: Complications related to percutaneous transarterial embolization of intracranial dural arteriovenous fistulas in 40 patients. AJNR Am J Neuroradiol 30:462-468, 2009

41. Mahmood A, Malik GM: Dural arteriovenous malformations of the skull base. Neurol Res 25:860-864, 2003

42. Malik GM, Mahmood A, Mehta BA: Dural arteriovenous malformation of the skull base with intraosseous vascular nidus. Report of two cases. J Neurosurg 81:620-623, 1994
43. Malik GM, Pearce JE, Ausman JI, Mehta B: Dural arteriovenous malformations and intracranial hemorrhage. Neurosurgery 15:332-339, 1984

44. Manabe H, Hasegawa S, Takemura A, Shafiqul IM, Ito C, Nagahata M: Contralateral inferior petrosal sinus approach for transvenous embolization of a dural arteriovenous fistula at isolated jugular bulb. Technical case report. Minim Invasive Neurosurg 46:366-368, 2003

45. Manabe S, Satoh K, Matsubara S, Satomi J, Hanaoka M, Nagahiro S: Characteristics, diagnosis and treatment of hypoglossal canal dural arteriovenous fistula: report of nine cases. Neuroradiology 50:715-721, 2008

46. Mascalchi M, Scazzeri F, Prosetti D, Ferrito G, Salvi F, Quilici N: Dural arteriovenous fistula at the craniocervical junction with perimedullary venous drainage. AJNR Am J Neuroradiol 17:1137-1141, 1996

47. McDougall CG, Halbach VV, Dowd CF, Higashida RT, Larsen DW, Hieshima GB: Dural arteriovenous fistulas of the marginal sinus. AJNR Am J Neuroradiol 18:1565-1572, 1997

48. Meckel S, Lovblad KO, Abdo G, Ruiz DS, Delavelle J, Radue EW, et al: Arterialization of cerebral veins on dynamic MDCT angiography: a possible sign of a dural arteriovenous fistula. AJR Am J Roentgenol 184:1313-1316, 2005

49. Meckel S, Maier M, Ruiz DS, Yilmaz H, Scheffler K, Radue EW, et al: MR angiography of dural arteriovenous fistulas: diagnosis and follow-up after treatment using a time-resolved 3D contrast-enhanced technique. AJNR Am J Neuroradiol 28:877-884, 2007

50. Mironov A: Dural arteriovenous fistula of the inferior petrosal sinus producing contralateral exophthalmus. Neuroradiology 36:619-621, 1994

51. Miropolsky V, da Costa LB, Marotta TR, Spears J: Endovascular therapy of hypoglossal canal AVFs presenting with orbital symptoms. Can J Neurol Sci 36:745-750, 2009

52. Miyachi S, Ohshima T, Izumi T, Kojima T, Yoshida J: Dural arteriovenous fistula at the anterior condylar confluence. Interv Neuroradiol 14:303-311, 2008

53. Moher D, Liberati A, Tetzlaff J, Altman DG, PRISMA Group: Preferred reporting items for systematic reviews and meta-analyses: the PRISMA statement. Ann Intern Med 151:264-269, W64, 2009

54. Nishimura S, Hirai T, Sasao A, Kitajima M, Morioka M, Kai Y, et al: Evaluation of dural arteriovenous fistulas with 4D contrast-enhanced MR angiography at 3T. AJNR Am J Neuroradiol 31:80-85, 2010

55. Okahara M, Kiyosue H, Tanoue S, Sagara Y, Hori Y, Kashiwagi J, et al: Selective transvenous embolization of dural arteriovenous fistulas involving the hypoglossal canal. Interv Neuroradiol 13:59-66, 2007

56. Ouanounou S, Tomsick TA, Heitsman C, Holland CK: Cavernous sinus and inferior petrosal sinus flow signal on threedimensional time-of-flight MR angiography. AJNR Am J Neuroradiol 20:1476-1481, 1999

57. Pan HC, Sun MH, Chen WH, Ting CC, Sheehan J: Minimally invasive approaches to treating chemosis of the eyes from unusual dural arteriovenous fistulae. Minim Invasive Neurosurg 52:222-228, 2009

58. Pei W, Huai-Zhang S, Shan-Cai X, Cheng G, Di Z: Isolated hypoglossal nerve palsy due to endovascular treatment of a dural arteriovenous fistula with Onyx-18. Interv Neuroradiol 16:286-289, 2010

59. Perkash I, Punj V, Ota DT, Lane B, Skirboll SL: Intracranial dural arteriovenous fistula causing a myelopathy. Spinal Cord 40:438-442, 2002

60. Pierot L, Chiras J, Meder JF, Rose M, Rivierez M, Marsault $\mathrm{C}$ : Dural arteriovenous fistulas of the posterior fossa draining into subarachnoid veins. AJNR Am J Neuroradiol 13:315323,1992 
61. Rhoton AL Jr: The posterior fossa veins. Neurosurgery 47 (3 Suppl):S69-S92, 2000

62. Rodesch G, Comoy J, Hurth M, Lasjaunias P: Jugular foramen arteriovenous shunt with subarachnoid hemorrhage. Skull Base Surg 1:132-136, 1991

63. Roy D, Raymond J: The role of transvenous embolization in the treatment of intracranial dural arteriovenous fistulas. Neurosurgery 40:1133-1144, 1997

64. San Millán Ruíz D, Gailloud P, Rüfenacht DA, Delavelle J, Henry F, Fasel JH: The craniocervical venous system in relation to cerebral venous drainage. AJNR Am J Neuroradiol 23:1500-1508, 2002

65. Shi ZS, Ziegler J, Gonzalez NR, Feng L, Tateshima S, Jahan $\mathrm{R}$, et al: Transarterial embolization of clival dural arteriovenous fistulae using liquid embolic agents. Neurosurgery 62:408-415, 2008

66. Sugiura Y, Nishizawa S: Arteriovenous fistula involving the inferior petroclival vein-case report. Neurol Med Chir (Tokyo) 51:45-47, 2011

67. Suzuki S, Lee DW, Jahan R, Duckwiler GR, Viñuela F: Transvenous treatment of spontaneous dural carotid-cavernous fistulas using a combination of detachable coils and Onyx. AJNR Am J Neuroradiol 27:1346-1349, 2006

68. Takemoto K, Tateshima S, Rastogi S, Gonzalez N, Jahan R, Duckwiler G, et al: Onyx embolization of anterior condylar confluence dural arteriovenous fistula. J Neurointerv Surg 6:e13, 2014

69. Tanoue S, Goto K, Oota S: Endovascular treatment for dural arteriovenous fistula of the anterior condylar vein with unusual venous drainage: report of two cases. AJNR Am J Neuroradiol 26:1955-1959, 2005

70. Terada T, Kinoshita Y, Yokote H, Tsuura M, Tanaka Y, Itakura T, et al: Clinical use of mechanical detachable coils for dural arteriovenous fistula. AJNR Am J Neuroradiol 17:1343-1348, 1996

71. Tirakotai W, Benes L, Kappus C, Sure U, Farhoud A, Bien $\mathrm{S}$, et al: Surgical management of dural arteriovenous fistulas with transosseous arterial feeders involving the jugular bulb. Neurosurg Rev 30:40-49, 2007

72. Trolard P: Recherches dur l'anatomie du système veineux de l'encéphale et du crâne [thesis]. Paris: Faculté de Médecine de Paris, 1868, pp 1-32

73. Tsutsumi S, Yasumoto Y, Ito M, Oishi H, Arai H: Posterior fossa dural arteriovenous fistula as a probable cause of congestive myelopathy. Case report. Neurol Med Chir (Tokyo) 48:171-175, 2008

74. Tubbs RS, Ammar K, Liechty P, Wellons JC III, Blount JP, Salter EG, et al: The marginal sinus. J Neurosurg 104:429_ 431, 2006

75. Turner RD, Gonugunta V, Kelly ME, Masaryk TJ, Fiorella DJ: Marginal sinus arteriovenous fistulas mimicking carotid cavernous fistulas: diagnostic and therapeutic considerations. AJNR Am J Neuroradiol 28:1915-1918, 2007

76. Valdueza JM, von Münster T, Hoffman O, Schreiber S, Einhäupl KM: Postural dependency of the cerebral venous outflow. Lancet 355:200-201, 2000

77. van Rooij WJ, Sluzewski M, Beute GN: Intracranial dural fistulas with exclusive perimedullary drainage: the need for complete cerebral angiography for diagnosis and treatment planning. AJNR Am J Neuroradiol 28:348-351, 2007

78. Viñuela F, Fox AJ, Pelz DM, Drake CG: Unusual clinical manifestations of dural arteriovenous malformations. J Neurosurg 64:554-558, 1986
79. Wiesmann M, Padovan CS, Pfister HW, Yousry TA: Intracranial dural arteriovenous fistula with spinal medullary venous drainage. Eur Radiol 10:1606-1609, 2000

80. Willems PW, Brouwer PA, Barfett JJ, terBrugge KG, Krings $\mathrm{T}$ : Detection and classification of cranial dural arteriovenous fistulas using 4D-CT angiography: initial experience. AJNR Am J Neuroradiol 32:49-53, 2011

81. Willinsky R, TerBrugge K, Lasjaunias P, Montanera W: The variable presentations of craniocervical and cervical dural arteriovenous malformations. Surg Neurol 34:118-123, 1990

82. Yamada M, Miyasaka Y, Kitahara Y, Yada K, Kan S: Dural arteriovenous malformation involving the inferior petrosal sinus-case report. Neurol Med Chir (Tokyo) 34:300-303, 1994

83. Yang HC, Kano H, Kondziolka D, Niranjan A, Flickinger JC, Horowitz MB, et al: Stereotactic radiosurgery with or without embolization for intracranial dural arteriovenous fistulas. Neurosurgery 67:1276-1285, 2010

\section{Author Contributions}

Conception and design: Meckel. Acquisition of data: Meckel, Spittau, El-Sherifi, Hader, Singh, Motschall, Urbach. Analysis and interpretation of data: Meckel, Spittau. Drafting the article: Meckel, Spittau, San Millán, El-Sherifi. Critically revising the article: all authors. Reviewed submitted version of manuscript: all authors. Approved the final version of the manuscript on behalf of all authors: Meckel. Statistical analysis: Vach. Administrative/ technical/material support: Motschall. Study supervision: Meckel. Anatomical figure design: Spittau. Anatomical review: San Millán.

\section{Supplemental Information \\ Previous Presentation}

Parts of this work were presented at the 12th Congress of World Federation of Interventional and Therapeutic Neuroradiology (WFITN) held in Buenos Aires, Argentina, on November 10, 2013, and at the 37th European Society of Neuroradiology Annual Meeting held in Frankfurt, Germany, on September 29, 2013.

\section{Videos}

Video 1, Media Player. http://mfile.akamai.com/21490/wmv/ digitalwbc.download .akamai.com/21492/wm.digitalsource-naregional/jns14-377_video_1.asx.

Video 1, Quicktime. http://mfile.akamai.com/21488/mov/ digitalwbc.download.akamai.com/21492/qt.digitalsource-global/ jns14-377_video_1.mov.

Video 2, Media Player. http://mfile.akamai.com/21490/wmv/ digitalwbc.download.akamai.com/21492/wm.digitalsource-naregional/jns14-377_video_2.asx.

Video 2, Quicktime. http://mfile.akamai.com/21488/mov/ digitalwbc.download.akamai.com/21492/qt.digitalsource-global/ jns14-377_video_2.mov.

\section{Correspondence}

Stephan Meckel, Department of Neuroradiology, Neurocenter, University Hospital Freiburg, Breisacher Strasse 64, D-79106 Freiburg, Germany. email: stephanmeckel@gmail.com. 
APPENDIX TABLE 1. Literature database search strategies for systematic review on HCDAVFs: PubMed†

\begin{tabular}{|c|c|c|}
\hline Search & Query & No. of Hits \\
\hline$\# 1$ & Search "Central Nervous System Vascular Malformations"[MeSH] & 8970 \\
\hline \#2 & Search dural arteriovenous fistu|*[tiab] & 1511 \\
\hline \#3 & Search dural arterio-venous fistul*[tiab] & 33 \\
\hline$\# 4$ & Search davf*[tiab] & 620 \\
\hline \#5 & Search condylar vein*[tiab] & 27 \\
\hline \#6 & Search condylar confluenc*[tiab] & 11 \\
\hline$\# 7$ & Search marginal sinus*[tiab] & 235 \\
\hline \#8 & Search hypoglossal canal*[tiab] & 208 \\
\hline$\# 9$ & Search "Jugular Veins"[MeSH] & 9500 \\
\hline$\# 10$ & Search jugular vein*[tiab] & 10,878 \\
\hline$\# 11$ & Search ACV[tiab] OR ACC[tiab] OR IPS[tiab] & 14,595 \\
\hline$\# 12$ & Search skullbase[tiab] & 30 \\
\hline$\# 13$ & Search skull-base[tiab] & 7645 \\
\hline$\# 14$ & Search jugular foramen*[tiab] & 720 \\
\hline$\# 15$ & Search jugular bulb*[tiab] & 938 \\
\hline$\# 16$ & Search intra-osseous[tiab] & 490 \\
\hline$\# 17$ & Search intraosseous*[tiab] & 4276 \\
\hline$\# 18$ & Search inferior petrosal sinus*[tiab] & 533 \\
\hline$\# 19$ & Search foramen magnum[tiab] & 1684 \\
\hline \#20 & Search craniocervical[tiab] OR cranio-cervical[tiab] & 1879 \\
\hline \#21 & Search \#1 OR \#2 OR \#3 OR \#4 & 9663 \\
\hline$\# 22$ & $\begin{array}{l}\text { Search \#5 OR \#6 OR \#7 OR \#8 OR \#9 OR \#10 OR \#11 OR \#12 OR \#13 OR \#14 OR \#15 OR } \\
\text { \#16 OR \#17 OR \#18 OR \#19 OR \#20 }\end{array}$ & 47,852 \\
\hline \#23 & Search \#21 AND \#22 & 369 \\
\hline
\end{tabular}

$[\mathrm{MeSH}]=$ medical subject heading (including narrower terms in the MeSH hierarchy); [tiab] = Title, Abstract.

† Searched (yyyy-mm-dd) 2013-09-11.

* Truncation. 
APPENDIX TABLE 2. Literature database search strategies for systematic review on HCDAVFs: Web of Science†

\begin{tabular}{|c|c|c|}
\hline Set & No. of Hits & Query \\
\hline \#18 & 216 & \#17 AND \#3 \\
\hline \#17 & 49,128 & \#16 OR \#15 OR \#14 OR \#13 OR \#12 OR \#11 OR \#10 OR \#9 OR \#8 OR \#7 OR \#6 OR \#5 OR \#4 \\
\hline$\# 16$ & 2001 & ts=(craniocervical OR "cranio-cervical") \\
\hline$\# 15$ & 1665 & ts="foramen magnum" \\
\hline \#14 & 501 & ts="inferior petrosal sinus" \\
\hline$\# 13$ & 3738 & ts=("intra-osseous" or intraosseous) \\
\hline$\# 12$ & 877 & ts="jugular bulb" \\
\hline$\# 11$ & 677 & ts="jugular foramen*" \\
\hline$\# 10$ & 8711 & ts=(skullbase or "skull-base") \\
\hline$\# 9$ & 23,342 & ts $=(\mathrm{ACV}$ or $\mathrm{ACC}$ or IPS) \\
\hline \#8 & 8714 & ts="jugular vein"” \\
\hline$\# 7$ & 174 & ts="hypoglossal canal" \\
\hline \#6 & 129 & ts="marginal sinus"” \\
\hline \#5 & 7 & ts="condylar confluenc" \\
\hline \#4 & 27 & ts="condylar vein"” \\
\hline \#3 & 1766 & \#2 OR \#1 \\
\hline \#2 & 528 & ts=davf* \\
\hline$\# 1$ & 1746 & ts=("dural arteriovenous fistul"” or "dural arterio-venous fistul"”) \\
\hline
\end{tabular}

TS = topic.

$\dagger$ Update status: 2013-09-09. Searches were conducted in the following fields: Title, Abstract, Author Keywords, Keywords Plus. Databases included Science Citation Index Expanded (SCI-EXPANDED): 1945-present, Social Sciences Citation Index (SSCI): 1975-present, Arts \& Humanities Citation Index (A\&HCI): 1975-present, Conference Proceedings Citation Index-Science (CPCI-S): 1990-present, and Conference Proceedings Citation Index-Social Science \& Humanities (CPCI-SSH): 1990-present.

* Truncation. 
APPENDIX TABLE 3. Literature database search strategies for systematic review on HCDAVFs: Embase and Embase Alert†

\begin{tabular}{|c|c|c|}
\hline No. & Hits & Search Term \\
\hline 1 & $23,627,345$ & EM74; EA08 \\
\hline 2 & 610 & CT=DURAL ARTERIOVENOUS FISTULA \\
\hline 3 & 13,769 & CT=ARTERIOVENOUS FISTULA \\
\hline 4 & 1034 & 3 AND DURAL \\
\hline 5 & 2003 & DURAL ARTERIOVENOUS FISTUL* \\
\hline 6 & 57 & DURAL ARTERIO-VENOUS FISTUL* \\
\hline 7 & 731 & DAVF* $^{*}$ \\
\hline 8 & 2266 & 2 OR 4 OR 5 OR 6 OR 7 \\
\hline 9 & 32 & CONDYLAR VEIN* \\
\hline 10 & 13 & CONDYLAR CONFLUENC* \\
\hline 11 & 234 & MARGINAL SINUS* \\
\hline 12 & 242 & HYPOGLOSSAL CANAL* \\
\hline 13 & 7889 & CT=JUGULAR VEIN \\
\hline 14 & 18,787 & JUGULAR VEIN* \\
\hline 15 & 20,235 & ACV OR ACC OR IPS \\
\hline 16 & 55 & SKULLBASE \\
\hline 17 & 13,262 & SKULL-BASE \\
\hline 18 & 875 & JUGULAR FORAMEN* \\
\hline 19 & 1146 & JUGULAR BULB* \\
\hline 20 & 423 & INTRA-OSSEOUS \\
\hline 21 & 5083 & INTRAOSSEOUS \\
\hline 22 & 4 & INTRAOSSOUS OR INTRA-OSSOUS \\
\hline 23 & 735 & INFERIOR PETROSAL SINUS* \\
\hline 24 & 2570 & FORAMEN MAGNUM \\
\hline 25 & 2362 & CRANIOCERVICAL OR CRANIO-CERVICAL \\
\hline 26 & 63,698 & 9 TO 25 \\
\hline 27 & 306 & 8 AND 26 \\
\hline 28 & 281 & 27 NOT SU=MEDLINE \\
\hline
\end{tabular}

CT $=$ controlled term $($ EMTREE); EA08 = Embase Alert; EM74 = Embase 1974 to present; SU = subunit.

† Via DIMDI (www.dimdi.de). Update Status: Embase: 01.01.1974-11.09.2013; Embase Alert: 12.07.2013-11.09.2013.

* Truncation. 
APPENDIX TABLE 4. Summary of clinical presentation and venous drainage patterns for 120 HCDAVFs

\begin{tabular}{|c|c|c|c|}
\hline Authors \& Year & No. of DAVFs & Clinical Presentation (no. of fistulas) & Venous Drainage Pattern (no. of fistulas) \\
\hline Barnwell et al., 1990 & 6 & PT(4), OS(5) & IJV/VVP(6), OD(4), PM(1) \\
\hline Willinsky et al., 1990* & 1 & $\mathrm{PT}(1), \mathrm{OS}(1)$ & $\operatorname{VVP}(1), \mathrm{OD}(1), \mathrm{RC}(1)$ \\
\hline Rodesch et al., 1991 & 1 & HEM(1) & $\mathrm{PM}(1), \mathrm{RC}(1)$ \\
\hline Kuwayama et al., 1994 & 1 & $\mathrm{PT}(1), \mathrm{OS}(1)$ & $\operatorname{VVP}(1)$ \\
\hline Yamada et al., 1994 & 1 & $\mathrm{PT}(1), \mathrm{OS}(1)$ & $\operatorname{VVP}(1), O D(1)$ \\
\hline Malik et al., 1994 & 2 & $\mathrm{PT}(2)$ & IJV/VVP(2), IPS/CS(1) \\
\hline Mironov, 1994 & 1 & $\mathrm{PT}(1), \mathrm{cl} O S(1)$ & VVP(1), IPS/CS(1), cl OD(1) \\
\hline Mascalchi et al., 1996 & 2 & $\mathrm{MP}(2)$ & $\mathrm{PM}(2)$ \\
\hline Ernst et al., $1997^{\star}$ & 1 & $\mathrm{MP}(1)$ & PM(1) \\
\hline Lewis et al., $1997^{*}$ & 1 & PT(1), FND(1) & IJV(1), TS/SS(1), cl IJV(1) \\
\hline McDougall et al., 1997 & 14 & PT(11), OS(2), HEM(2), MP(1) & IJV/VVP(8), OD(2), RC(2), PM(1) \\
\hline Blomquist et al., 1998 & 1 & $\mathrm{PT}(1), \mathrm{HP}(1)$ & IJV/VVP(1) \\
\hline Hähnel et al., 1998 & 1 & $\mathrm{MP}(1)$ & $\mathrm{PM}(1), \mathrm{RC}(1)$ \\
\hline Kai et al., 1998 & 1 & HEM(1) & $\mathrm{PM}(1)$ \\
\hline Ernst et al., 1999 & 3 & PT(3), recurrence w/ OS(1) & IJV/VVP(3), OD(1), RC(1), TS/SS(1) \\
\hline Hurst et al., $1999^{*}$ & 1 & $\mathrm{MP}(1)$ & $\mathrm{PM}(1)$ \\
\hline Wiesmann et al., 2000 & 1 & $\mathrm{MP}(1)$ & $\mathrm{PM}(1)$ \\
\hline Kiyosue et al., 2001 & 1 & $\mathrm{PT}(1), \mathrm{OS}(1)$ & IJV/VVP(1), OD(1), SphS(1) \\
\hline Chen et al., 2001 & 2 & PT(2), OS(2) & IJV/VVP(1), IPS/CS(2), SPS(1), RC(2) \\
\hline Liu et al., $2001^{*}$ & 1 & OS(1) & IJV/VVP(1), OD(1), RC(1) \\
\hline Asakawa et al., 2002 & 1 & $\mathrm{MP}(1)$ & $\mathrm{PM}(1)$ \\
\hline Kiyosue et al., 2002* & 1 & Asymptomatic & IJV(1) \\
\hline Perkash et al., 2002 & 1 & $\mathrm{MP}(1)$ & IJV(1) \\
\hline Mahmood \& Malik, 2003* & 1 & $\mathrm{PT}(1)$ & IJV/VVP(1) \\
\hline Manabe et al., 2003 & 1 & OS(1) & VVP(1), IPS(1) \\
\hline Arai et al., 2004 & 1 & $\mathrm{PT}(1), \mathrm{OS}(1)$ & IJV/VVP(1), OD(1), cl CS(1), RC(1) \\
\hline Chng et al., 2004 & 1 & $\mathrm{MP}(1)$ & PM(1) \\
\hline Tanoue et al., 2005 & 2 & $\mathrm{PT}(1), \mathrm{MP}(1), \mathrm{OS}(1)$ & PM(1), OD(1) \\
\hline Turner et al., 2007 & 2 & $\mathrm{PT}(2), \mathrm{OS}(2)$ & stenotic IJV/VVP(2), OD(2) \\
\hline Tirakotai et al., 2007 & 5 & $\mathrm{PT}(5), \mathrm{HP}(1), \mathrm{OS}(1)$ & IJV(5), TS/SS(1), VVP(1) \\
\hline Miyachi et al., 2008 & 8 & $\mathrm{PT}(8), \mathrm{OS}(2), \mathrm{HP}(3)$ & IJV/VVP(8), IPS(3) \\
\hline Liu et al., 2008 & 1 & $\mathrm{PT}(1), \mathrm{HP}(1)$ & IJV/VVP(1) \\
\hline Abiko et al., 2008 & 2 & $\mathrm{PT}(2)$ & IJV/VVP(2), IPS/CS(1) \\
\hline Manabe et al., 2008 & 9 & $\mathrm{PT}(9), \mathrm{HP}(1)$ & IJV/VVP(9), IPS(5) \\
\hline Tsutsumi et al., 2008 & 1 & $\mathrm{PT}(1), \mathrm{MP}(1)$ & VVP(1), IPS/CS(1) \\
\hline Shi et al., $2008^{*}$ & 1 & $\mathrm{PT}(1)$ & IJV/VVP(1) \\
\hline Byun et al., 2009 & 1 & HEM(1) & PM(1) \\
\hline Jung et al., $2009^{*}$ & 4 & $\mathrm{PT}(3), \mathrm{FND}(1)$ & IJV/VVP(4), IPS/CS(1), SS(1), PM(1) \\
\hline Miropolsky et al., 2009 & 3 & PT(1), OS(3) & IJV/VVP(2), OD(3), SphS(1), RC(2) \\
\hline Pan et al., 2009* & 1 & $\mathrm{PT}(1), \mathrm{OS}(1)$ & IJV(1), OD(1) \\
\hline Guo et al., $2010^{*}$ & 1 & HEM(1) & $\mathrm{PM}(1), \mathrm{RC}(1)$ \\
\hline Pei et al., 2010 & 1 & $\mathrm{PT}(1)$ & IJV/VVP(1) \\
\hline Lee et al., 2011 & 1 & $\mathrm{PT}(1), \mathrm{OS}(1)$ & IJV/VVP(1), OD(1) \\
\hline Choi et al., 2012 & 5 & $\mathrm{PT}(4), \mathrm{OS}(2), \mathrm{HP}(2), \mathrm{FND}(1)$ & IJV/VVP(4), IPS/CS(2), OD(1), SS/TS(1), RC(1), cl CS/IPS(1) \\
\hline Takemoto et al., 2014 & 3 & $\mathrm{PT}(3)$ & IJV/VVP(3), SS(3) \\
\hline Cyril et al., 2013 & 1 & $\mathrm{PT}(1)$ & $\operatorname{lJV}(1)$ \\
\hline Choi et al., 2013 & 10 & $\mathrm{PT}(7), \mathrm{OS}(4), \mathrm{HP}(4), \mathrm{MP}(1), \mathrm{FND}(2)$ & IJV/VVP(7), IPS/CS(4), OD(4), RC(2), PM(1) \\
\hline
\end{tabular}


APPENDIX TABLE 4. Summary of clinical presentation and venous drainage patterns for 120 HCDAVFs (continued)

\begin{tabular}{lcll}
\hline \multicolumn{1}{c}{ Authors \& Year } & No. of DAVFs & Clinical Presentation (no. of fistulas) & \multicolumn{1}{c}{ Venous Drainage Pattern (no. of fistulas) } \\
\hline Gentric et al., 2013 & 1 & OS(1) & IJV(1), OD(1), SS(1), RC(1) \\
\hline Own cases & 7 & PT(7), OS(1), HP(1) & IJV/VVP(7), cl IJV(1), IPS/CS(2), bilat IPS/CS(1), OD(1), SS/TS(1) \\
\hline
\end{tabular}

$\mathrm{cl}=$ contralateral; $\mathrm{CS}=$ cavernous sinus; $\mathrm{FND}=$ focal neurological deficit; $\mathrm{HEM}=$ intracranial hemorrhage; $\mathrm{HP}=$ hypoglossal palsy; $\mathrm{MP}=$ myelopathy; OD = orbital venous drainage; OS = orbital symptoms; $\mathrm{PM}=$ perimedullary and perimesencephalic drainage $; \mathrm{RC}=$ retrograde cortical drainage; SphS = sphenoparietal sinus; $\mathrm{SPS}=$ superior petrosal sinus; $\mathrm{SS}=$ sigmoid sinus; TS = transverse sinus.

* Series included various types of DAVFs and the indicated number corresponds to HCDAVFs.

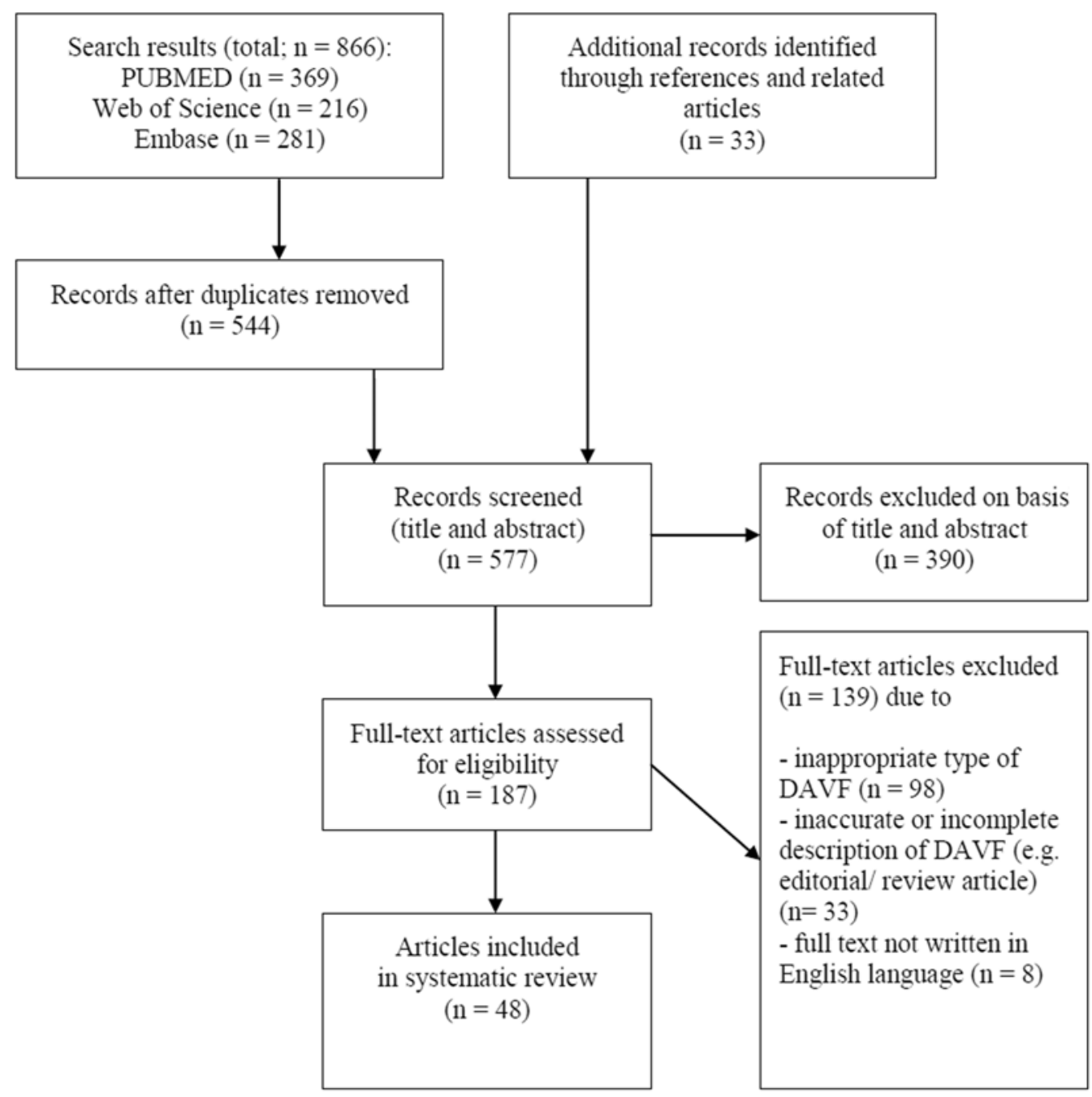

APPENDIX FIG. 1. Flow diagram of literature screening for systematic review on HCDAVFs. 
APPENDIX TABLE 5. Summary of treatments, complications, and outcomes in 120 HCDAVFs

\begin{tabular}{|c|c|c|c|c|c|}
\hline Authors \& Year & $\begin{array}{l}\text { No. of } \\
\text { DAVFs }\end{array}$ & Treatment Modality (no. of fistulas) & $\begin{array}{l}\text { Complication (no. of } \\
\text { fistulas) }\end{array}$ & $\begin{array}{c}\text { Angiographic } \\
\text { Outcome (no. } \\
\text { of fistulas) }\end{array}$ & $\begin{array}{c}\text { Clinical } \\
\text { Outcome (no. of } \\
\text { fistulas) }\end{array}$ \\
\hline Barnwell et al., 1990 & 6 & $\begin{array}{l}\text { TAE(glue/others 1), TVE(coils 1), TAE(glue/PVA)+ } \\
\text { TVE(coils+silk 1; coils 1), none(1)† }\end{array}$ & VT(2), TIA(1) & $\mathrm{CO}(5) \dagger$ & $\mathrm{CR}(5) \dagger$ \\
\hline Willinsky et al., 1990* & 1 & TAE(PVA 1) & & $\mathrm{CO}(1)$ & $\mathrm{CR}(1)$ \\
\hline Rodesch et al., 1991 & 1 & TAE(glue 1) & & $\mathrm{CO}(1)$ & $\mathrm{CR}(1)$ \\
\hline $\begin{array}{l}\text { Kuwayama et al., } \\
1994\end{array}$ & 1 & TVE VVP(coils 1) & & $\mathrm{CO}(1)$ & $\mathrm{CR}(1)$ \\
\hline Yamada et al., 1994 & 1 & $\mathrm{TAE}+\mathrm{RT}(1)$ & & $\mathrm{CO}(1)$ & $\operatorname{PR}(1)$ \\
\hline Malik et al., 1994 & 2 & TAE+surgery(1), surgery(1) & & $\mathrm{CO}(2)$ & $\mathrm{CR}(2)$ \\
\hline Mironov, 1994 & 1 & Surgery(1) & & $\mathrm{PO}(1)$ & $\mathrm{PR}(1)$ \\
\hline Mascalchi et al., 1996 & 2 & Surgery(1), TAE(glue 1) & & $\mathrm{CO}(1), \mathrm{NS}(1)$ & $\mathrm{CR}(1), \mathrm{PR}(1)$ \\
\hline Ernst et al., $1997^{*}$ & 1 & TAE(glue 1) & & $\mathrm{CO}(1)$ & $\mathrm{PR}(1)$ \\
\hline Lewis et al., $1997^{*}$ & 1 & TAE+StereoS+surgery(1) & & $\mathrm{PO}(1)$ & $\mathrm{CR}(1)$ \\
\hline $\begin{array}{l}\text { McDougall et al., } \\
1997\end{array}$ & 14 & $\begin{array}{l}\text { TAE(glue 2), TVE(il IJV 4; cl IJV 1), TAE(PVA 5; } \\
\text { ethanol 2)+TVE(coils 7), TAE(PVA)+surgery(1) }\end{array}$ & Transient HP(1) & $\mathrm{CO}(12), \mathrm{PO}(2)$ & $\mathrm{CR}(14)$ \\
\hline Blomquist et al., 1998 & 1 & None(1) & & $\mathrm{SpO}(1)$ & $\mathrm{CR}(1)$ \\
\hline Hähnel et al., 1998 & 1 & TAE(Ethibloc 1) & & $\mathrm{CO}(1)$ & $\operatorname{PR}(1)$ \\
\hline Kai et al., 1998 & 1 & TAE(liquid coils+EVAL 1) & & $\mathrm{CO}(1)$ & $\mathrm{NS}(1)$ \\
\hline Ernst et al., 1999 & 3 & $\begin{array}{l}\text { TAE+TVE(PVA 2; coils 2), TAE(PVA } \\
\text { 1)+StereoS+TVE(coils 1) }\end{array}$ & & $\mathrm{CO}(2), \mathrm{PO}(1)$ & CR(2), NS(1) \\
\hline Hurst et al., 1999* & 1 & TAE(PVA 1) & & $\mathrm{CO}(1)$ & $\operatorname{PR}(1)$ \\
\hline $\begin{array}{l}\text { Wiesmann et al., } \\
2000\end{array}$ & 1 & TAE(glue 1) & & $\mathrm{CO}(1)$ & $\mathrm{PR}(1)$ \\
\hline Kiyosue et al., 2001 & 1 & TVE(1) & & $\mathrm{CO}(1)$ & $\mathrm{CR}(1)$ \\
\hline Chen et al., 2001 & 2 & NS EVT(1), NS EVT+RT(1) & & $\mathrm{PO}(2)$ & PR(1), Death(1) $\ddagger$ \\
\hline Liu et al., 2001* & 1 & TAE(glue 1) & & $\mathrm{CO}(1)$ & $\mathrm{CR}(1)$ \\
\hline Asakawa et al., 2002 & 1 & TAE(PVA)+surgery(1) & & $\mathrm{NS}(1)$ & $\mathrm{PR}(1)$ \\
\hline Kiyosue et al., 2002* & 1 & None(1) & & $\mathrm{SpO}(1)$ & $\mathrm{CR}(1)$ \\
\hline Perkash et al., 2002 & 1 & None(1) & & $\mathrm{NS}(1)$ & $\mathrm{PR}(1)$ \\
\hline $\begin{array}{l}\text { Mahmood \& Malik, } \\
2003^{*}\end{array}$ & 1 & NS EVT+surgery(1) & & $\mathrm{NS}(1)$ & $\mathrm{CR}(1)$ \\
\hline Manabe et al., 2003 & 1 & TVE(cl IPS 1) & & $\mathrm{CO}(1)$ & $\mathrm{CR}(1)$ \\
\hline Arai et al., 2004 & 1 & TVE(1) & & $\mathrm{CO}(1)$ & $\mathrm{CR}(1)$ \\
\hline Chng et al., 2004 & 1 & TAE(glue 1) & & $\mathrm{PO}(1)$ & $\mathrm{PR}(1)$ \\
\hline Tanoue et al., 2005 & 2 & TAE(glue 1), TVE(surgically exposed frontal vein 1) & & $\mathrm{CO}(2)$ & $\mathrm{CR}(1), \mathrm{PR}(1)$ \\
\hline Turner et al., 2007 & 2 & TVE(1), TAE+TVE(Onyx+coils 1) & & $\mathrm{CO}(2)$ & $\mathrm{CR}(2)$ \\
\hline Tirakotai et al., 2007 & 5 & TAE+surgery(5) & CC instability(1), HP(1) & $\mathrm{CO}(4), \mathrm{PO}(1)$ & $\mathrm{CR}(4), \mathrm{PR}(1)$ \\
\hline Miyachi et al., 2008 & 8 & TAE(NS 1), TVE(coils 4), TAE+TVE(NS+coils 3) & Transient HP(1) & $\mathrm{CO}(8)$ & $\mathrm{CR}(8)$ \\
\hline Liu et al., 2008 & 1 & TAE+surgery(1) & & $\mathrm{CO}(1)$ & $\mathrm{CR}(1)$ \\
\hline Abiko et al., 2008 & 2 & $\operatorname{TVE}(2)$ & & $\mathrm{CO}(2)$ & $\mathrm{CR}(2)$ \\
\hline Manabe et al., 2008 & 9 & $\begin{array}{l}\text { TAE(NS 2), TVE(coils 2), TAE+TVE(PVA+coils 1), } \\
\text { none(4) }\end{array}$ & $\mathrm{HP}(1)$ & $\begin{array}{l}\mathrm{CO}(4), \mathrm{SpO}(4) \\
\mathrm{PO}(1)\end{array}$ & $\mathrm{CR}(8), \mathrm{PR}(1)$ \\
\hline Tsutsumi et al., 2008 & 1 & $\operatorname{TVE}(1)$ & & $\mathrm{CO}(1)$ & $\mathrm{PR}(1)$ \\
\hline Shi et al., $2008^{*}$ & 1 & TAE(coils+PVA+Onyx 1) & & $\mathrm{CO}(1)$ & $\mathrm{CR}(1)$ \\
\hline Byun et al., 2009 & 1 & TAE(glue 1) & Brainstem infarct(1) & $\mathrm{CO}(1)$ & $\mathrm{PR}(1)$ \\
\hline Jung et al., $2009^{*}$ & 4 & TVE(4) & & $\mathrm{CO}(4)$ & $\mathrm{CR}(4)$ \\
\hline $\begin{array}{l}\text { Miropolsky et al., } \\
2009\end{array}$ & 3 & $\begin{array}{l}\text { TAE(PVA+glue 1), TVE(1), TVE(surgically exposed SOV } \\
\text { 1) }\end{array}$ & & $\mathrm{CO}(2), \mathrm{PO}(1)$ & $\mathrm{CR}(3)$ \\
\hline Pan et al., 2009* & 1 & StereoS(1) & & $\mathrm{CO}(1)$ & NA \\
\hline
\end{tabular}


APPENDIX TABLE 5. Summary of treatments, complications, and outcomes in 120 HCDAVFs (continued)

\begin{tabular}{|c|c|c|c|c|c|}
\hline Authors \& Year & $\begin{array}{l}\text { No. of } \\
\text { DAVFs }\end{array}$ & Treatment Modality (no. of fistulas) & $\begin{array}{l}\text { Complication (no. of } \\
\text { fistulas) }\end{array}$ & $\begin{array}{c}\text { Angiographic } \\
\text { Outcome (no. } \\
\text { of fistulas) }\end{array}$ & $\begin{array}{c}\text { Clinical } \\
\text { Outcome (no. of } \\
\text { fistulas) }\end{array}$ \\
\hline Guo et al., 2010* & 1 & Surgery(1) & & $\mathrm{CO}(1)$ & $\mathrm{CR}(1)$ \\
\hline Pei et al., 2010 & 1 & $\operatorname{TAE}($ Onyx 1) & $\mathrm{HP}(1)$ & $\mathrm{CO}(1)$ & $\mathrm{CR}(1)$ \\
\hline Lee et al., 2011 & 1 & TVE VVP(1) & & $\mathrm{CO}(1)$ & $\mathrm{CR}(1)$ \\
\hline Choi et al., 2012 & 5 & TVE(il IJV 3; cl IJV 1; VVP 1) & & $\mathrm{CO}(4), \mathrm{PO}(1)$ & $\mathrm{CR}(4), \mathrm{PR}(1)$ \\
\hline Takemoto et al., 2014 & 3 & TVE(coils+Onyx 2; Onyx only 1) & Transient HP(1) & $\mathrm{CO}(3)$ & $\mathrm{CR}(3)$ \\
\hline Cyril et al., 2013 & 1 & TVE(coils 1) & & $\mathrm{CO}(1)$ & $\mathrm{CR}(1)$ \\
\hline Choi et al., 2013 & 10 & $\begin{array}{l}\text { TAE(NBCA 1), TVE(il coils 7; cl coils 1), TAE + TVE } \\
\text { (PVA + coils; 1) }\end{array}$ & & $\mathrm{CO}(10)$ & $\mathrm{CR}(6), \mathrm{PR}(4)$ \\
\hline Gentric et al., 2013 & 1 & TVE(il coils+direct puncture SOV 1) & & $\mathrm{CO}(1)$ & $\mathrm{CR}(1)$ \\
\hline Own cases & 7 & TAE(Onyx 1), TVE(il IJV coils 4; cl IJV Onyx 1), none(1) & $H P(1), V T(1)$ & $\mathrm{CO}(6), \mathrm{SpO}(1)$ & $\mathrm{CR}(7)$ \\
\hline
\end{tabular}

$\mathrm{CC}=$ common carotid; $\mathrm{cl}=$ contralateral; $\mathrm{CO}=$ complete occlusion; $\mathrm{CR}=$ complete recovery; $\mathrm{EVAL}=$ ethylene vinyl alcohol copolymer; $\mathrm{HP}=$ hypoglossal palsy; il = ipsilateral; NA = not available; NS = not specified; others = hypertonic glucose, $\mathrm{PVA}$, and Gelfoam; $\mathrm{PO}=$ partial occlusion; $\mathrm{PR}=$ partial recovery; $\mathrm{RT}=$ radiotherapy; $\mathrm{SpO}=$ spontaneous occlusion; StereoS = stereotactic surgery; $\mathrm{VT}=$ venous sinus thrombosis.

† Only one asymptomatic fistula with antegrade drainage was not treated.

* Series included various types of DAVFs and only the indicated number corresponds to HCDAVFs.

$\ddagger$ Death was related to cerebellar hemorrhage after the patient had been lost to follow-up for 1 year following incomplete endovascular HCDAVF occlusion. 